\title{
Understanding Top Management Involvement in SDLC Phases
}

\author{
A. Alzayed, $\mathrm{PhD}$ \\ Computer \& Information System Department \\ Public Authority for Applied Education and Training \\ (PAAET) \\ P.O.Box: 65130, Almansouriya, Kuwait 35652
}

\author{
Abdulwahed Khalfan, $\mathrm{PhD}$ \\ Computer \& Information System Department \\ Public Authority for Applied Education and Training \\ (PAAET) \\ P.O.Box: 20124, Safat, Kuwait 13062
}

\begin{abstract}
One of the most essential factors in the success of system implementation has been recognized as top management support and involvement. Few research, however, have addressed the question of what sort of engagement is necessary through the various stages of the system development life cycle (SDLS). Given the many challenges to top management involvement and support in the various SDLC phases. The objective of this research was twofold. First, to examine the relationship between top management support and the phases of SDLC in order to give guidance for top management practices to ensure the success of information system projects. Second, this study sought to investigate approaches of motivating top management to participate in the SDLC as well as the barriers that hinder them from doing so. This study investigates the function of top management in various phases of system implementation, which will help us in understanding the support mechanism from top management in various SDLC stages. To achieve this goal, the author performed a qualitative study in five different firms in Kuwait, interviewing top management, project management, system analysts, and IT managers. The research established criteria for top management participation and indicated that top management should be involved primarily in the planning and implementation phases, as well as other phases as needed.
\end{abstract}

\section{Keywords}

SDLC,TM involvement, TM support, TM motivation, TM Involvement barriers

\section{INTRODUCTION}

The definition of "top management" varies based on the size and structure of the organization, but in general, "Top management'should include members of the senior executive team who can make strategic decisions which align the internal structures and processes of an organization with its environment by setting rules and procedures and submitting resources (Carpenter, Geletkanycz, \& Sanders, 2004; Pettigrew, 1992). Top management refers typically to the highest level individuals in an organization such as President, CEO, Executive Director, senior management, and Chairman or Vice president (Denis and Denis, 1995). In this study the authors interchangeably uses the words' Senior Management' and' Top Management'. The concept of TMS was initially developed in strategic information systems management by (Kearns, 2007; Cicmil \& Hodgson, 2006). Top management support (TMS) is regarded as one of the main success factors (SFs) that have been related to project success (young and Jordan, 2008). According to Hertatiand Syafarudin(2020), top management is accountable for giving general guidelines and support for information system (IS) activities. The amount of support offered by top management for organizational IS can be a critical element in influencing the effectiveness of all information system-related operations. However, providing this support from the management side is often not easy, because top management has multiple strategic tasks to do towards their organization.

Nevertheless, the top management participation inIT system implementation considered to be as an essential part in IS support, They can offer right strategic direction, as well as symbolic and material support for an IS project. Their actions can be critical in allocating limited organizational resources to guarantee the project's success (Elbanna, 2013).Therefore, The involvement and participation of top management helps an organization to adapt dynamically to various environmental changes. They also have an essential role in successfully directing their organization through changes, and deciding on the different systems the organization needs (Ragu-

Nathan et al., 2004; Griffin \& Morehead, 2014). They can also influence the integration of the development and implementation of ISs within the organization heavily (Hsia \& Rubin, 2019).

Given the importance of TMS and the grey areas surrounding it, The authorsare eager to undertake research within this area. This research advance on preceding literature by analyzing TMS practices in the sense of its relationship to the SDLC phases. SDLC is a structured analysis that consist of a series of stages, such as planning, analysis, designing, implementation and testing and finally maintenance (Licorish\&MacDonell, 2017). The SDLC is one of many possible system development approaches. An SDLC can be used in conjunction with many development models, such as the traditional waterfall model, the joint application model, and rapid application development (RAD).

The objective of this study is two-fold. First, this study aimed to address the top management support and involvement within the SDLC in order to provide guidelines for top management practices to ensure the success of information system projects. Second, as top management support is an important factor for project success, this study also aimed to explore the ways of motivating top management to be involved in the SDLC and the barriers preventing them from doing so. The study will provide answers to the following unsolved questions:

RQ1: How do TM describe their experiences of participation within the phases of SDLC?

RQ2: How do PM, ITM, and SA describe their experiences of 
TM's participation within the phases of SDLC?

RQ3: How do TM, PM, ITM, and SA describe the challenges and barriers to TM's participation within the phases of SDLC?

RQ4: How do TM, PM, ITM, and SA describe the motivation of TM's participation within the phases of SDLC?

\section{LITRETURE REVIEW \\ 2.1 Top management Support}

The role of senior or top management support (TMS) in the ISdevelopment process is believed to be essential. According to Wiener, Cram \& Remus (2017), leadership, commitment, and senior management involvement are necessary for the development, implementation, and maintenance of an effective system for the development of software and to gain organization's benefits and that of all interested parties.TMS is seen as one of the key factors in all phases of project planning and implementation (de Sousa Jabbouret al. 2018).Studies found that TMS must bepractical and applied in the project contextand should not be ignored (Wang, et al, 2019).Otherstudyargues that TMS is important and can definitelyraise the possibility of project software success (Young \& Jordan, 2008; Zwilkael, 2008a-b). According to Hsu, et al., (2019), TMS results in greater time-based efficiency, quality of design, financial performance and product success.

TM support in IS development is a level at which top management recognizes the value of information systems and want to get involved in activities related to itsdevelopment (Kanavittaya, 2016; Pasha et al., 2018).Darma et al., (2018),stated that TMS is the ability to supply the authority and resources required for the success of the information system project.Licorish\&McDonell (2017) found that the senior management not only provides the necessary resources for the process but it is also imperative that they guide and keep a check on the progress of the development team through active involvement. One of the most critical roles of senior management is determined by Madampe (2017) that they can shape the culture with personality and produce an essential effect on the planning and management of the software development life cycle (SDLC).

Furthermore, Akgun et al. (2017) suggest that senior management can help the project managers in maintaining their commitment to software development, aid them in overcoming obstacles such as infrastructure issues, insufficient resources, need for outsourcing, etc. Similarly, Haynie, Mossholder \& Harris (2016) presents that software development heavily relies on the role and active involvement of top management in acquiring the required resources, getting design approvals, securing the necessary legality and allocation of the required authority.

Meanwhile, the top management may come across some barriers or obstacles that prevent them to effectively get involved within the development process. Antony et al., (2019) stated that the lack of support from top management is one of the causes of failures in the implementation of the systems companies.According to Akgun et al. (2017), obstacle refers to the factor that avoids the senior management form making efficient involvement and contribution to the software development process. The study by Niazi et al. (2016) explores the obstacles to the participation of senior management within the software development phases. They stated that there are chances that the software developer does not show empathy towards the management personnel who are technically challenged. The observations show that the developer although show agreement to the involvement of senior management, but exhibits zero empathy for them if they lack technical experience or sufficient knowledge about the process. The developers openly accept the involvement and opinion of the management who is technically sound but do not understand or resist the choices or views of the individuals who are technically challenged.Moreover, factors like difficulty in communicating, contrasting work conditions, imprecision, and uncompassionate attitudes were reported by studies (Fitriani, Rahayu\&Sensuse, 2016). Haynie, Mossholders\& Harris (2016) suggest that the absence of motivation in senior management also hinders active involvement. In such cases, it becomes difficult for the development team to convince the senior management for their actions or planning. Khan \& Keung (2016) contributes this absence of motivation to the lack of adequate knowledge among the senior management.

Although many studies have suggested that TMS is crucial to the project success, These suggestions do not provide guidelines for its achievement (Young \& Jordan, 2008). Which often leaves top management uncertain about their roles and remains reluctant to engage in the system implementation because they don't know what is expected from them (Dong et al., 2009). According to Wagner, 2018, one of the problems facing top management during software project implementation. They are educated to deal withorganization's strategy issues, and they see the IT strategy implementation as an operational technique which belongs to other people down the hierarchy. They usually don't see the connection between the two strategies, which results in projects failure.According to Sony, M., and Naik, S. (2020), top management support is a very wide phrase, and future research should study the role of top management in various phases of industry system implementation, which would help us understand the support mechanism from top management in different phases of implementation. Therefore, What we need is a clear degree of engagement that will not only adjust the viewpoint of top management, but can also affect their actions throughout the project more closely (Collier, Fishwick\& Floyd, 2004). Top managers should be aware of their presence and support, so that they will not cross the line and seek to impose their agendas which might be inconvenient for the project manager and the project itself (Swink, 2000).

\subsection{System Development Life Cycle (SDLC)}

SDLC is a structured analysis, formal, logical, and well-defined method consisting of a set of ordered steps. In addition, the development process is from top to bottom that uses a series of phases, such as planning, analysis, designing, implementation, testing and finally maintenance (Licorish\&MacDonell, 2017. The SDLC is one of many possible system development approaches. An SDLC can be used in conjunction with many development models, such as the traditional waterfall model, the joint application model, and rapid application development (RAD).Many researchers have stated that the involvement of senior management is crucial in all phases of SDLC. Madampe, 2017, stated that top management support is important during the planning stage. According to Hoda\&Murugesan (2016), senior management would be responsible to keep a check on the capturing of the necessary information related to the development of software during the planning phase. For project success, top management support is required throughout the project's life cycle [Nah et al. 2001]. During the IS development, the top management can adequately comprehend the operations, current position and progress of the development process. They need to take care of what is working, where the risks are, and what improvements are required within the procedures [Hoda\&Murugesan, 2016].

Software Engineering literature has been focusing on implementing formalized methods such as (Waterfall and 
Spiral methodologies) or other more advanced techniques like ( Agile and Lean approaches) to scheduling, planning and delivering software products on time and available budget (Kalliamvakou et al. 2019). The Software Engineering Body of Knowledge (Bourque et al., 2014) attempt to address team dynamics and software engineers teamwork but ignores the top management engagement in SDLC phases(Kalliamvakou et al. 2019). On the other hand, In a typical software development life-cycle, in each stage, the business organization faces different challenges which require different types of TMS practices.

Literatures have investigated the user involvement in the IS implementation and how to map this involvement into the SDLC process activities within the public sector (Ben Rehouma, M. 2020). Other studies emphasized on top management participation, top management behaviour or top management commitment in Enterprise Systems (ES) lifecycle. Neufeld et al., (2007) andKe\& Wei, (2008) explored the practices of top management leadership style needed in the Enterprise System (ES) Life-Cycle. Staehr in 2010, discussed how, where and why ' top management support ' correlates to Enterprise System (ES) success throughout its life-cycle. A further study also examined the alignment between leadership style and each phase of the ES life-cycle (adoption, implementation, assimilation, and extension) and its effects towards the success of the system in the organization (Shao et al., 2016).

SDLC adds continuity to the different processes involved with software development activities and does not stop until all requirements and future needs have been met. The primary benefit of using a software development life cycle is the leverage it has over the development process. It assists in ensuring that the system meets all of the requirements. SDLC, on the other hand, has several drawbacks. It does not fit well in situations where there is a high degree of uncertainty or where there are excessive overheads. It guides development efforts with a focus on planning but does not promote innovative input or creativity across the lifecycle. As a result of these factors, more companies choose to use Agile and other incremental rather than linear methodologies.

According to the above academic literature and the results of the previous studies. Still, there is a gab of a clearlydefined TMS practices approach within each phase of SDLC processwhich can assistexecutive managersto participate in the implementation of software development projects, and comprehend what practices of TMS betterfits with which SDLC phase. The result of this study will help organizations to put in place the best TMS practices and raise the possibility of project success. The main objective of this study is to provide both Top management, senior management and project management with a better understanding of the role and practices of top management within the SDLC phased.To achieve this goal, this study is based on conducting a qualitative semi-structured interview with top management, project management, system analyst and IT managerinfivedifferent organizations as described in the research methodology section.

\section{RESEARCH METHODOLOGY}

To gain insights of the relationship between top management and SDLC, and to point out in which phases of the SDLC the support and involvement is important. The authorsconducted a qualitative research method which consist of a demographic questionnaire and a semi-structured interview with open ended questions as a data collection tools for the research. Semistructured interviews were conducted using an interview guide that covered questions related to the topic of TMS in the workplace context. Semi-structured interviews are useful in terms of allowing freedom to the interviewer to explore, probe and ask follow-up questions that are not pre-determined in the interview guide and deepen the conversation to specific topics or subject areas to maximize concreteness and immediacy of the interview questions (Patton, 2002; Pickard, 2013).

To obtain robustness we chose five different types of companies to gain sufficient information richness. Since our attention was on TMS within the SDLC phases, we made sure that each company chosen had there IS project in its implementation, roll-out and use SDLC phases (Markus, 2000). The research sample consisted of firms from various industries, including healthcare, information technology, government section, food production, and academia)in order to prevent contextual bias.Furthermore, Cross-section samples are expected to increase the generalizability of the Results. (Geyskens et al., 1996; Hooley et al., 1990; Jaworski and Kohli, 1993).

\subsection{Data collection}

A Semi-structured interviews with open-ended questions was used to collect the data and test the research hypothesis (Runesson \& Host, 2009). The interview question were done based on the research topic which we wanted to explore. In total, 20 interviews were conducted, five companies were chosen to participates in the research interview, four interviews were conducted in each company premises. All interview questions were asked in English but the interviewees were given the right to answer the questions in both English or Arabic language depending on the interviewees preference and each interview lasted between 20-30 minutes. To support the Semi-structured interview process the author developed an interview guide with formal question set. The interview guide contained 29 questions and they were divided into four sections including: TMS, behavior, challenges, and attitude. The use of the interview guide allowed the authorsto collect data in consistent and unbiased fashion. The questions were sufficiently general to cover a wide range of participants' experiences, and others narrow enough to explore experiences specific to each participant. The questionswere based on the authors prior knowledge and were proof read by someone external to the research that had expertise in software development process. One of the authorsarranged with each of the 20 participants an appropriate date and time to conduct the interviews with them and began each interview with a short explanation of the research conducted and its goal. The author started each interview in the same way by first introducing himself, then welcoming and thanking the participant for agreeing to participate, asking them to turn off their mobile phones. However, the interviewees were given the right to answer or reject any question they don't feel comfortable to answer. A consent letter has to be signed by the interviewees before conducting the interview to take his/her permission for conducting and audio-recorded the interview. The reason for recording is to have a full description of what was said in the interview [Welshan, 1995]. During each interview, a short demographic questionnaire was used as well to collect factual information about the participant age, education and work experiences. All data given by the participants were treated as useful and crucial to the interviewer. Necessary Documents were also collected by the author from each involved company as complementary for the data collected. These document were company profile, Project management documents, Software development documents etc.

Once the interviews were completed, the authors downloaded the audio files on to a password-protected computer. The 
authors then transcribed each of the interviews verbatim and reviewed transcripts to confirm the material was accurately transcribed prior to deleting the audio files and progressing to the analysis process.

\subsection{Demographics of the interview participants}

Regarding the current position of the participants, for the $5 \mathrm{TM}$, 3 were general managers, 1 was CEO, and the remaining TM was a senior manager. All ITM were IT managers, all PM were project managers, and all SA were system analysts. Table 1 summarizes years of working at current job for the participants. On average, participants have worked at the current position for 8.55 years $(\mathrm{SD}=6.72)$. When looking at the specific roles, the average years of working at the current job working were longest for ITM (Mean $=11.00, \mathrm{SD}=12.59)$ and shortest for $\mathrm{PM}($ Mean $=5.80, \mathrm{SD}=12.59)$.

\section{Table 1: Years working at current job}

\begin{tabular}{|l|l|l|l|l|}
\hline Role & Mean & SD & Min & Max \\
\hline TM & 6.80 & 3.27 & 3 & 10 \\
\hline ITM & 11.00 & 12.59 & 3 & 33 \\
\hline PM & 5.80 & 3.03 & 2 & 10 \\
\hline SA & 10.60 & 3.21 & 7 & 15 \\
\hline Overall & 8.55 & 6.72 & 2 & 33 \\
& & & & \\
\hline
\end{tabular}

Note: SD = standard deviation.

\subsection{Data Analysis}

Responses from the 20 interview participants were imported into NVivo 12 Pro (QSR International Pty Ltd., Doncaster, Australia) for analysis. Using thematic analysis (Braun \& Clarke, 2006; Fereday \& Muir-Cochrane, 2006; Thomas, 2006; Alhojailan, 2012) the steps outlined in Braun and Clarke were modified and applied (2006) in order to search for themes within the responses of the 20 participants in an attempt to provide a rich and detailed account of the participants' perceptions of top management support for SDLC.

The aim of the analysis was to produce an overall description of the dataset using semantic (rather than latent) themes in an inductive approach (rather than theoretical) as thematic analysis is defined as "a method for identifying, analyzing, and reporting patterns (themes) within data" (Braun \& Clarke, 2006, p. 79).

The topics and themes that emerged from the responses were the focus of this data analysis. The analysis proceeded with three separate readings of the interview responses. A list was made of all the topics of discussion that arose in the participants' responses. Themes were then developed by grouping the topics that fit under a particular heading. For example, all topics relating to the barriers that prevent TM to join in the SDLC were grouped together under the theme 'Barriers for TM to participate in SDLC'.

In order to get familiar with the data, for data management and coding, all interview transcripts were loaded into NVivowhich allow the authorsto subdivide the data and eventually categorize them into themes and sub-themes. Iterative and inductive methods were used to perform a thematic analysis (Braun \& Clarke, 2006). Transcripts were read several times to ensure familiarity with the dataset.Themes and subthemes were grouped, organized and checked to ensure they were reflective of the dataset. Coding included the discovering of meaning and content patterns that addressed the research question. Following that, all codes were checked for relations and associations.Themes and subthemes were categorized, structured, and double-checked to ensure they were applicable to the dataset. In other words, all responses were grouped under the appropriate themes. Miscellaneous theme were also examined to see if they could be fit under another theme. Themes that seems irrelevant were discarded. As the study continued, any inconsistencies or conflicting views were considered and addressed.

\subsection{Quality of the Interview Data}

To ensure that the quality of the data meets the standards of trustworthiness and reliability. Validity and reliability increase transparency and decrease potential for researcher bias in qualitative research (Singh, 2014). In qualitative research, validity and reliability can be assessed in terms of the credibility, dependability, confirmability, and transferability of the results of the study (Lincoln \& Guba, 1985).

\subsection{Credibility}

Credibility of qualitative research findings indicates the study findings are an accurate representation of the interview data (Lincoln \& Guba, 1985). The credibility of the findings for this study was enhanced by a prolonged interview, a similar set of interview questions with each participant and by accurately capturing each participant's perceptions of top management support for SDLC by recording the interviews.

Member checking was also used to enhance the credibility of the findings and reduce potential for researcher bias by actively involving the research participant in checking and confirming the results (Birt, Scott, Cavers, Campbell, \& Walter, 2016). After transcribing the audio files, the authors contacted five participants (one per organization) by email and ask them to review their interview responses to affirm the accuracy of their interview transcript and to ensure that no information was missing or miss-recorded. After the authors completed the write-up for the findings, five participants (one per organization) were contacted by email and shared with the whole results findings. These five participants were requested to review the study findings and provide their feedback. All five participants had responded to this request, reviewed the findings, and indicated that they agreed with the contents, which was an indication that credibility of this study was inherent in the accurate descriptions and interpretations of the findings.

\subsection{Dependability}

Dependability can be established through a process of auditing by another researcher concurring with the decision trails at each stage of the research process (Tobin \& Begley, 2004).

Two outside auditors (a PhD colleagues in the same field with the authors) assisted with the examination of the dependability of the study. The auditors and the authors were both knowledgeable persons about the interview subject matter, had a thorough understanding of the theories about the study, and had the ability to see meaningful conceptual breaks and a respondent's statements (Campbell et al., 2013).

The authors and the auditors met in a conference room on campus. The meeting was about 4 hours and 30 minutes. The authors first explained the research purpose of the 
study, the design of the study, how the semi-structured interviews were conducted, and how the audio data were transcribed to the research assistant. The authors also presented 1) the methods section of the study, 2) the interview transcripts, and 2) the NVivo coding output, to the auditor. This is to make sure that the process of the research is logical, traceable, and clearly documented (Schwandt, 2001).

To ensure the NVivo coding output correctly reflected the responses of the interview transcripts, the authors and the auditors examined the coding files for two randomly selected participants with 51 codes (1 ITM with 21 codes and 1 TM with 30 codes). The auditors agreed with 40 (15 codes for the ITM and 25 codes for the TM) out of the 51 codes $(78.4 \%)$ The authors and the auditors then examined the 11 codes $(6$ codes for ITM and 5 codes for TM) that the auditors had questions with. The authors then provided further clarifications for how the coding was created for these 11 codes.

Through the research process and descriptions of the research, a study would be deemed dependable if the study findings could be replicated with similar participants in similar conditions (Koch, 2006). The dependability of the data was hence established and confirmed by engaging the external auditors to confirm the appropriateness of the research design and the interview and data collection process, and the accuracy of the interview transcripts and the NVivo coding output.

\subsection{Confirmability}

Confirmability refers to the objective demonstration of the interview data representing the participants' responses and not the researcher's biases or viewpoints (Tobin \& Begley, 2004). In this study, the authors demonstrated confirmability by describing how conclusions and interpretations were established, and exemplifying that the findings were derived directly from the data by exhibiting rich quotes from the participants that depict each emerging theme. Furthermore, the authors also made a consistent effort to bracket assumptions and biases so as not to superimpose his own expectations or subjective interpretations on the interview data (Smith, 2004).

\section{TRANSFERABILITY}

Transferability refers to findings that can be applied to other settings or groups (Tobin \& Begley, 2004). A qualitative study is said to havetransferability if the results findings are meaningful to individuals not involved in the study. In this study, to help readers assess the findings and associate the results with their own experiences, the authors provided sufficient demographic information on the interview participants and detailed descriptions of the research context The transferability of the qualitative findings in this study was further enhanced by purposive sampling of participants from various industrial sectors who were able to provide relevant knowledge regarding top management support for SDLC (Anney, 2014).

\section{DATA ANALYSIS RESULTS}

This section introduces the nine themes that emerged from the interpretive analysis of the semi-structured interview.

\subsection{Theme 1: TM experience of SDLC}

This theme describes attitudes of TM and how TM communicated with project team in SDLC.Figure 1 summarizes TM involvement experience in the SDLC phases, including (1) TM were involved in SDLC ( $\mathrm{N}=20$, with $5 \mathrm{TM}, 5 \mathrm{ITM}, 5 \mathrm{PM}$, and 5 SA), (2) positive attitudes of TM (non-TM participants only, $\mathrm{N}=15$, with 5 ITM, 5 PM, and 5 SA), (3) high level of participation (non-TM participants only, $\mathrm{N}=15$, with $5 \mathrm{ITM}, 5$ $\mathrm{PM}$, and $5 \mathrm{SA}$ ), (4) regular communication between TM and project team $(\mathrm{N}=17$, with $5 \mathrm{TM}, 4 \mathrm{ITM}, 3 \mathrm{PM}$, and $5 \mathrm{SA})$,

\section{TM experience of SDLC}

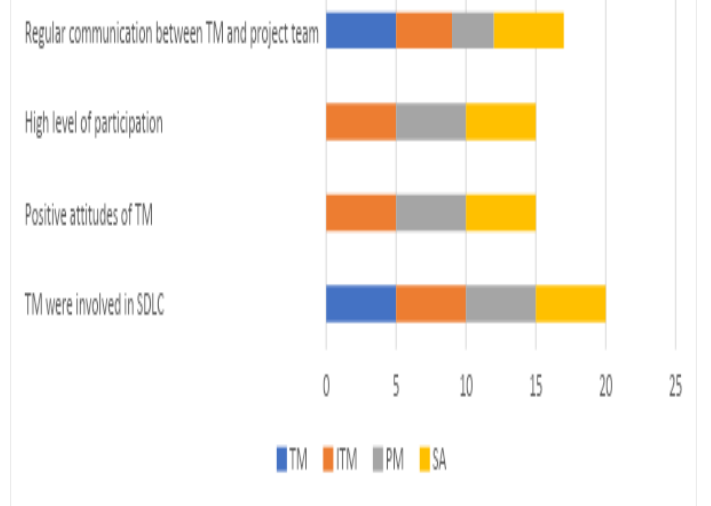

Figure 1: TM experience of SDLC

\subsubsection{Sub-theme 1: Positive attitudes and high involvement of TM in SDLC}

According to the participant prospective, Involving TM with IT department during the SDLC is essential, all of the 20 participants indicated that TM were involved in the SDLC in their organizations. An TM stated: "I always get connected with the people associated with the system" and "always make sure that the status of system implementation is always on my agenda". In the planning phase the TM were involved so they can make sure that the project is consistent with the goals and aims of the organization. It is important to the TM to ensure that goals and objectives of the organization are supported by the final outcome of the new system.

During the planning phase, TM seemed to have positive attitudes and were highly involved, according to the employees participated in the interview, including the ITM, the PM, and the SA. The employees highly praised the attitudes of TM during planning phase. For example, an ITM said "He [the TM] was very supportive and involved all the way.". An SA also provided a similar statement for the support TM provided during SDLC: "100 percent of the support [from the TM] that makes the project a success. In all phases of SDLC, we [the IT team] have received support from TM.". The supportive attitudes of TM provided positive influence on the project, though promoting team and departmental cooperation, providing the necessary resources on time, and committing all stakeholders to the project

\subsubsection{Sub-theme 2: How TM communicate with project team in SDLC TM view on how they communicate with project team in SDLC}

TM communicationthrough SDLC phases was done either through meetings or by receiving a weekly and monthly management reports. Communication is very important, as communication can help avoid ambiguity and contribute to the success of the project. An ITM said "At the beginning of the project we always communicate with $T M$ " so that we can "in sync with them" and "discuss with them the proposed new 
system". The frequency of regular meetings varies. TM and project team members may meet "weekly", "twice a week" or "once or twice a month".

In addition to regular meetings, the ITM stated that depending on "how important the system is to the organization and the urgency of the matter", TM have also "got an open door for IT people" so the project team can meet with the TM whenever needed or "when they [the project team] complete a major task or phase in the SDLC". This is so "if there is any obstacle they [the project team] should escalate quickly". For example, as a TM stated: "In some cases, if a problem needs to be resolved immediately, they[the project team] require a meeting or I call for a meeting if I want to urgently investigate about the system. My work procedure is to let them inform me about any problems they face during the project as soon as possible, and not leave it until it gets bigger." Note that for an urgent matter, TM has provided several ways for the IT people to contact him/her, including "email, phone or social media" in order to "solve any urgent problems and difficulties they face during the implementation of the system".

\section{Non-TM view on how TM communicate with project team in SDLC}

Non-TM, including ITM, PM, and SA, generally had similar views as the TM regarding how TM communicate with project team in SDLC. The employees felt "We need to communicate regularly with TM" and they did meet with the TM on a regular basis, whether it was "weekly or twice a month", "monthly", or "quarterly", which highly "depends on his [the TM] time schedule".

An ITM did point out that the project team did not meet with TM on a regular basis, rather, "We [the IT team] only communicate with TM when needed. Because he is very busy with other things.". The time the IT team met with the TM may be (1) when the project reached a milestone ("whenever we [the IT team] finish a big task or phase in the SDLC we usually make a presentation for him to get his feedback", and (2) when the TM desired to know the progress of the project ("Sometimes he [the TM] call for a meeting as well to ask about the progress of the system").

Two PM also indicated that they did not meet with

TM on a regular basis and only met the TM

- when they need the TM's help to solve an issue, for example, a PM stated "Because they are mostly busy they usually don't participate in system progress. We only meet them when there is a problem with another department that we need to solve.", or

- when there are "major deliverables", for example, a PM stated It depends, "For the important milestones we have for example, after one month we need to have user acceptance testing (UAT), TM has to be communicated and informed about it. Also going live for the new system has to be communicated with TM".

Note that PM seemed to have less communication with the TM as they go further in the project. As a PM further point out that "Mostly we [the project team] meet with TM to learn about his needs and requirements at the start of the project. His needs are becoming very minimal as we go further in the project.".

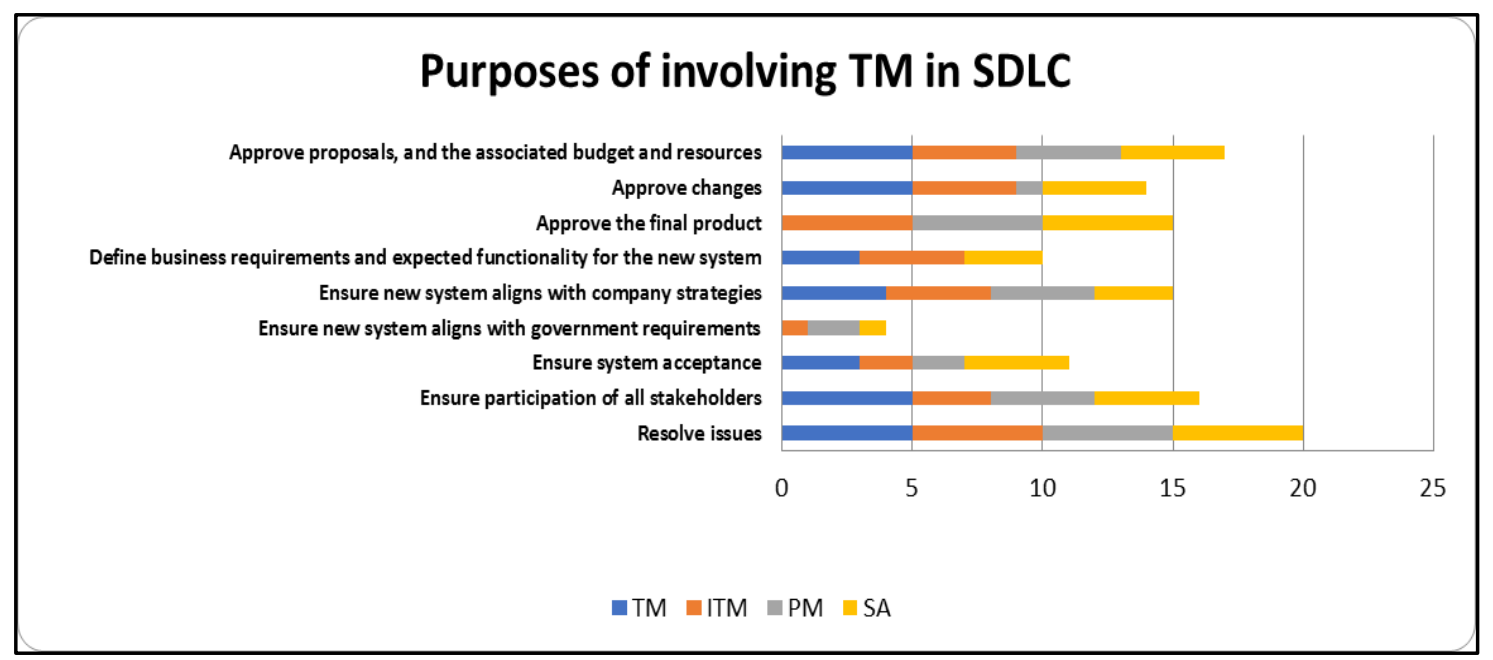

\subsection{Theme 2: Purposes of involving TM in SDLC}

This theme describes the nine purposes of involving TM in SDLC.Figure 2 summarizes purposes of involving TM in SDLC, including:

(1) approve proposals, and the associated budget and resources ( $\mathrm{N}=17$, with 5 TM, 4 ITM, 4 PM, and 4 SA),

(2) approve changes ( $\mathrm{N}=14$, with $5 \mathrm{TM}, 4 \mathrm{ITM}, 1 \mathrm{PM}$, and 4 SA),

(3) approve the final product ( $\mathrm{N}=15$, with $0 \mathrm{TM}, 5 \mathrm{ITM}, 5$ $\mathrm{PM}$, and $5 \mathrm{SA}$ ),

(4) define business requirements and expected functionality for the new system ( $\mathrm{N}=10$, with $3 \mathrm{TM}, 4 \mathrm{ITM}, 0 \mathrm{PM}$, and 3 SA),

(5) ensure new system aligns with company strategies $(\mathrm{N}=15$, with 4 TM, 4 ITM, 4 PM, and 3 SA),

(6) ensure new system aligns with government requirements ( $\mathrm{N}$ $=4$, with 0 TM, 1 ITM, 2 PM, and $1 \mathrm{SA}$ ),

(7) ensure system acceptance ( $\mathrm{N}=11$, with $3 \mathrm{TM}, 2 \mathrm{ITM}, 2$ $\mathrm{PM}$, and $4 \mathrm{SA}$ ),

(8) ensure participation of all stakeholders $(\mathrm{N}=16$, with $5 \mathrm{TM}$, 3 ITM, 4 PM, and 4 SA), and

(9) resolve issues ( $\mathrm{N}=20$, with $5 \mathrm{TM}, 5 \mathrm{ITM}, 5 \mathrm{PM}$, and 5 SA).

Involving TM in SDLC is essential, as one PM pointed out, "Indeed, this [involving TM in SDLC] is one of the critical factors in the success of the project.". An SAsummarizes why it is important to include TM in SDLC:

"For example, they [TM] are the ones who decide to accept the 
system or not, they know the strategy of the company and where the company will be heading in the future, they can know whether or not this system would be aligned with the strategy of the company. At the end we are technical people and our decision would be based on the technical aspect, but the top management should take the business decision and how to initiate the project."

If TM is not involved in SDLC, "their requirements are not clearly described, which will also result in incorrect expectations resulting in incorrect deliverables and ultimately a wasted

system investment". "It is therefore important to involve top management from the start of the project and the end of the project and during the project if there are any variations affecting the company as a whole." as pointed by an ITM.

\subsubsection{Sub-theme 1: Purposes of involving TM at the beginning of the project (i.e., the planning and Analysis phase of SDLC)}

There are several purposes of involving TM at the beginning of the project (i.e., the planning phase of SDLC), including (1) define business requirements and expected functionality for the new system, (2) ensure new system aligns with company strategies, (3) ensure new system aligns with government requirements, (4) approve proposals, and the associated budget and resources, (5) ensure participations of all stakeholders, and (6) Defining responsibility and authority for all stakeholders.

\section{Ensure the new system meet business requirements, expected functionality, government requirements, and company strategies}

For IT professionals, the first step of starting an IT project for a new system is to understand what the business requirements, the expected functionality, and government requirements for the new system are, and make sure that the new system aligns with company strategies. The planning phase of SDLC is very important for the TM to involved as an SA pointed out: "As a system analyst, I will need them [TM] most in the gathering requirements phase and in the initial design, without going through the design process deeply. Those requirements should be coordinated with all departments to know what tasks we need to implement, and what methods need to be conducted.". Another SA provided an example to explain why TM should be involved in the planning phase of SDLC:

"After operating on Microsoft platform for a period of time, we realized that this platform has some limitation so we can either update this platform or replace it with another platform. We had to go to the chief executive to help us find the right answer. Hence, we had to make a presentation for the CEO showing various solutions based on budget, timeline and license number and the system's ability to cover the company's processes. CEO needed to ensure this system aligned with the company's strategy."

As TM "sees an overall picture of the company and know the company's strategy and where the company is heading in the future", at the beginning of the SDLC, "TM should explain its [the organization] business requirements and tell IT people what the system should do and leave the technical requirements to IT staff'. This is the advantages from involving TM from the start of the SDLC as TM canmake sure that "the scope [of the new system] will cover the whole company", "the company strategic requirements and the department requirements will be clear [to the project team]" and "make sure the objectives of the organization are implemented".

In other words, as an ITM stated: "When the top management has been involved from the start of the project, they can demonstrate leadership by recognizing the strategic importance of the new system. All system requirements will be clear because TM is looking at the organization from a top level.". Thus, at the beginning of the SDLC, TM is responsible for providing the critical information such as, key business requirements criteria, objectives of the organization, and the expected functionality of the system so that "[organizational] policies and procedures are understood and followed [by the project team], the new system is consistent with the business objectives and will bring benefits [to the organization], and the new system can be integrated into the business processes of the organization". Furthermore, as oppose to the TM's duty, "it is the project owner's duty to ensure that they have a clear understanding of the top management expectations and that those expectations are realistic", as pointed out by a PM.

\section{Approve proposals, and the associated budget and resources}

Another purpose of involving TM at the beginning of the project is so the TM can approve the proposal, and the associated budget and resources for the new system. After the project team understand what the business requirements, the expected functionality, and government requirements for the new system are, the project team "must prepare its objectives and action plans to be discussed and approved" at the meeting with the TM for approval.

During the meeting with the project team, several aspects of the proposed new system will be discussed, including (1) "if the proposed system is feasible", (2) "if the proposed system is feasible has benefit to the company, (3) "if the project is consistent with the goals and aims of the organization", (4) "the necessary resources and budget", (5) "timeline", (6) "the system's ability to cover the company's processes".

After TM ensure that the proposal for the new system are "aligned with the business strategy of the organization and for the benefit of the company as a whole", and if the TM are satisfied with the new system justification from the start, "they [TM] can approve the new system plan, as well as approve all the necessary resources and budget". It is critical that TM allocate the appropriate budget and resources from project initiation. As an ITM pointed out "When the top management has been involved from the start of the project, they can demonstrate leadership by recognizing the strategic importance of the new system and subsequently allocating time and money for proper system employment.". Once the project team have the TM's approval, they can proceed with the system project.

\section{Ensure participations of all stakeholders}

As a TM suggested, "The most important thing of TM 's involvement at the start of the project is to get everyone involved and fall into line, and also assign project champions to the project. ensure the participation of the client [various departments]." Ensuring participations of all stakeholders is considered "vital for the success of the project and the acceptance of the product".

"When the IT project is initiated by TM, there is a higher chance of success.", based on a TM's experience. This is because "When employees realize that the project is being supported by TM, they will all be [more] supportive and dedicated.". Furthermore, for a project to be successful, all departments in an organization need to help. "TM chooses key persons from other department (key users) to work with us. When TM is involved these key users are dedicated." stated by 
an SA.

In sum, when senior management takes ownership of the project, they go beyond their ability to ensure cooperation from other departments, which will help the project team work smoothly with other departments, and thus generate greater engagement in the overall organization.

\subsubsection{Sub-theme 2: Purposes of involving TM in SDLC in the middle of the project (Design Phase)}

There are two purposes of involving TM in the middle of the project, including

(1) approve changes, and (2) resolve issues.

\section{Approve changes}

As a TM stated, "there are always big challenges coming from the IT project". When changes of the new system need to be made, depending on the type of the changes, TM may need to be involved. Typically, if the system changes are large and affect the operation of the entire organization company, then TM has to interfere. On the other hand, if the changes are minor, then TM usually would leave the decision to the IT people and the department manager.

For example, a TM stated,

"If the change is big and affect the whole company, then Yes, I [TM] need to interfere to know if the change or update has a positive or negative effect on the operation of the company. Otherwise, if the change is small and it only affect one department, then I let the manager of the concern department to work on the issue with the IT department to solve it."

ITMs further provided examples as to when a decision from the top management is needed for changes during the implementation process, which included (1) "when there is a change in the project timeframe and cost of the project", and (2) "when there is a need to change internal procedures or policies".

In sum, when the changes impact all departments in the business, TM is needed for "gaudiness, feedback, and approval". This is because (1) "any big change has to be aligned with the company strategy and the cost of the change has to be discussed with TM" as indicated by an SA, and (2) it may require the TM to "make the new changes applicable to all departments" as indicated also by an SA.

\section{Resolve issues}

Even though TM and the project team often meet on a regular basis, there may be issues that need to be resolved urgently or overcome during the implementation of the system. TM can help "if there is an issue or a problem that arises during the phases of the project and the project manager is unable to solve it". One important advantage of involving TM in the SDLC is to resolve "issues", "difficulties", "conflicts between departments", or "user resistance" during the implementation of the system.

Several employees had described their past experiences of encountering difficulties during the implementation phase of new system and how TM helped resolve the issues. For example, an ITM stated:

"Yeah, for example, in the process of converting or transferring data to a the Prime Health Care system, which is usually a very challenging task, and people who do this job often have other work to do on their day-to-day bases, so it becomes a challenge between us and the departments responsible for carrying out this task. Then we needed the CEO 's decision to solve the problem by, for example, giving overtime or bonuses to the department concerned." an SA stated:

"Yes, when we decided to go for Oracle ERP there was some IT people who refused the idea of having the Oracle ERP and made a lot of problems. We had to go to the TM to solve the problem."

and a PM stated:

"Yes, When we changed the manual system in the corporate department we faced user resistance from the department manager, we had to get the support from TM to make the conversion from the manual system and force the department to agree and use the new system.".

Indeed, during the project cycle, TM need to be involved to "help resolve any obstacles or challenges that may arise". TM can "act as an escalating point and help resolve issues beyond the project manager" and can "serve as a primary point of contact for internal and external stakeholders" to accelerate the process of the IT project and thereby contribute to the success of the project.

\subsubsection{Sub-theme 3: Purposes of involving TM in SDLC at the end of the project (post- implementation) \\ There are two purposes of involving TM at the} end of the project, including (1) approve the final product and (2) ensure system acceptance.

\section{Approve the final product}

After department managers have accepted the system and the sign off of the system is received, the project team present the final system to the TM and department managers to (1) examine if the initial set of requirements and the expectations are met, and (2) "show him [TM] what the system can do, i.e. all the system capabilities requested by stakeholders, [and] the reports he [TM] requested". After all departmental managers have agreed on the results of the system, the TM will grant his/her final sign-on approval. An SA and PM described their experience of the final product presentation as follows:

"Yes, once we've decided to go live for the Prime Health Care system, we've had a meeting with CEOs and departmental managers, and we've presented the system to them to explain the progress made during the project phases and the challenges and risks that we've faced out during the project, the outputs and outcomes that we've had, and what our expectations are and what our needs are after we've gone live. This presentation was important to take up their opinions and suggestions and to update them on the project."

In sum, one of the purposes of involving TM at the end of the project is to gain approval for the final product. As a PM stated: "It is important to present the system functionality to TM at the sign-off stage and to show him how the system fulfils the organizational requirements and to ensure that all business objectives are met before [TM] signing the acceptance approval."

\section{Ensure system acceptance}

After the TM grant final approval of the new system the project team need to implement the new system in the organization. TM need to "demonstrate leadership by recognizing the strategic importance of the new system" and ensure that "the new system is integrated into the business processes of the organization", as stated by an ITM. In other words, TM need to "ensure system acceptance" in the implementation phase and post-implementation phase

When there is user resistance, "management can also enforce changes to the system and make users adopt those 
changes". The purpose of involving TM in SDLC at the end of the project is to "resolve any human resistance to the new system, and to get everyone to buy into the system to be involved in post-implementation to resolve any resistance from users" as concluded by an SA.

A PM summarized his experience of how TM resolved user resistance in the organization:

"Yes, When we changed the manual system in the corporate department we faced user resistance from the department manager, we had to get the support from TM to make the conversion from the manual system and force the department to agree and use the new system.".

In sum, as a PM indicated: "TM must guide and support the project at all stages of the SDLC because, as with his support, all departments and stakeholders will be more eager to participate and use the new system".

\subsection{Theme 3: Phases of SDLC that TM should be involved}

This theme discussed the most phases that TM should be involved in within the SDLC phases. TM should be involved in all phases of SDLC. As shown in Figure 3, TM should be included in the SDLC (1) at the beginning of the project, i.e., the planning and designing phase ( $\mathrm{N}=20$, with 5 TM, 5 ITM, 5 $\mathrm{PM}$, and $5 \mathrm{SA}$ ), (2) at the end of the project, i.e., the implementation and post-implementation phase $(\mathrm{N}=20$, with 5 TM, 5 ITM, 5 PM, and 5 SA), and (3) at the other stages of the project ( $\mathrm{N}=11$, with $3 \mathrm{TM}, 4 \mathrm{ITM}, 4, \mathrm{PM}$, and $0 \mathrm{SA}$ ).

- roles of TM at each phase of SDLC (planning, analysis, designing, implementation and testing and final maintenance)

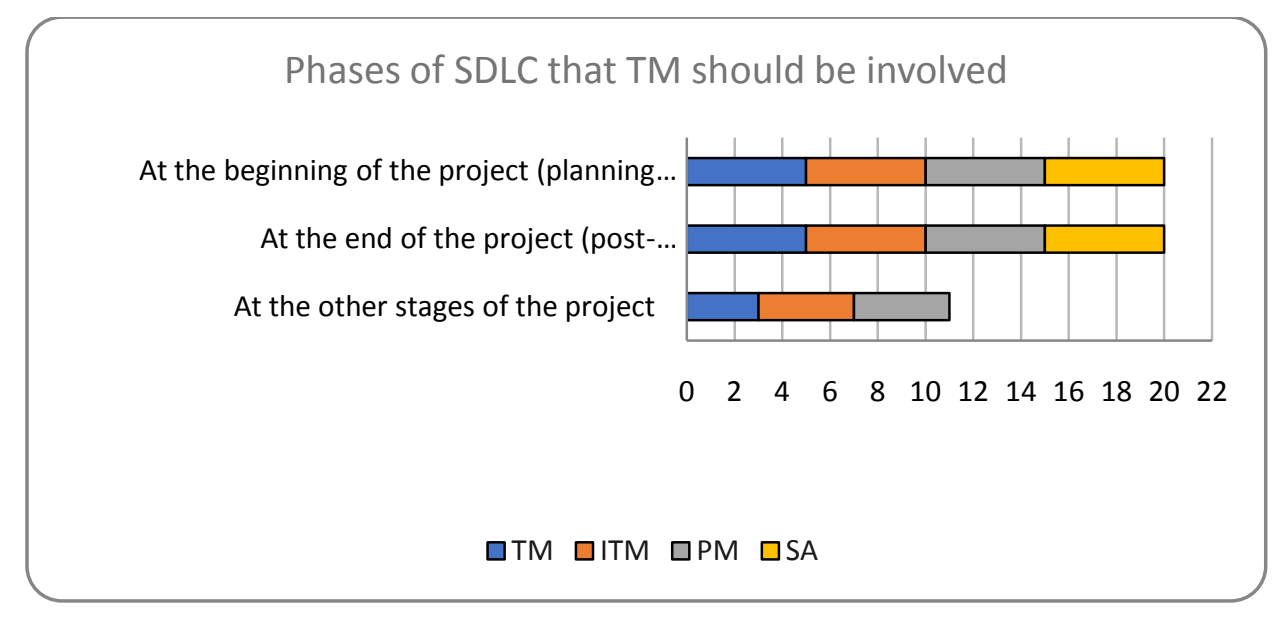

Figure 3: Phases of SDLC that TM should be involved

As pointed out by a TM that "I think, the most important phases of the SDLC in which TM should be involved are the project initiative phase and the post implementation phase. Sometimes in other phases as well when they are needed.", TM should be involved in all phases of SDLC, especially the phase of the project initiative and the phase of post-implementation.

For IT professionals to design a new system, a clear understanding of the requirements for the new system is extremely important. As an SA stated:

"In my opinion, TM is most important in the collection of requirements and in the design phase, without going deep into the design. We need to know his goals, policies and procedures for the new system while gathering requirements,

what kind of system features we need to incorporate, what kinds of processes need to be implemented, will these processes be coordinated with all departments?".

"If TM were involved with the system from the start or in the testing session, they will help in the design or the development of the system.", mentioned by a PM. According to the interview participants, the advantages of involving TM at the beginning of the project are that (1) company strategic requirements will be clear, (2) the departments' requirements will be clear, (3) stakeholders will be more committed and serious, (4) key success criteria and the expected output of the system will be defined, and (5) the necessary resources can be acquired. A TM's statement summarizes the importance of involving TM at the beginning of the project

"I think the advantages from involving TM from the start is that the company strategic requirements will be clear and the departments' requirements as well. Sometimes users are limited to their day-to-day operations and their requirements are to cover this day-to-day scope because they are limited to what they see and cannot see across other departments and the processes shifting from one department to another. Therefore, when the requirements come from a management perspective, this scope can be increased covering the whole company. Involving top management from the start, therefore, improves the functionality and the requirements process for any system to be implemented. Users themselves are also improving the way they adopt to the system or the attention they give to the system. If they know there's support coming from management, they will be more committed and serious."

TM should also be involved at the end of the project, i.e., the implementation / post-implementation phase. The primary advantage of involving TM at the end of the project is to "ensure the acceptance of the system", as there might be users resisting to adopt the new system. As an SA stated: TM can "enforce end-use to use the system at the end lof the project]".

Finally, in addition to the beginning and the end of the project, TM should be also involved at the other stages of the project in case "there are many variations affecting the company as a whole", which may require TM's attention. However, note that as in ITM further emphasized, "At the same time, [at the other stages of the project] you don't need to go to top management and update your system every day, you just need to show or approve the milestones, deliverables and contractual issues.". This point of view was also supported by the SA ("I don't need their [TM] involvement too much in the development and testing"), the TM ("At the other stages of the $S D L C$, the TM should be informed only but not to interfere"), 
and the PM (Perhaps [involving TM] in the development phase, but a small part).

In sum, "TM must be involved in the initiative phase of the project, and in the post-implementation phase in order to ensure system acceptance and sometimes in other phases as well." as concluded by a TM.
This theme identified risk of involving TM in SDLC.Although there are several advantages for involving TM in SDLC, there are also risk for doing so. Figure 4 summarize the risk of having TM in SDLC, including (1) request unnecessary project details ( $\mathrm{N}=7$, with $2 \mathrm{TM}, 2$ ITM, $2 \mathrm{PM}$, and $1 \mathrm{SA}),(2)$ have requirements out of system capability $(\mathrm{N}=$ 4 ,

\subsection{Theme 4: Risk of involving TM in SDLC}

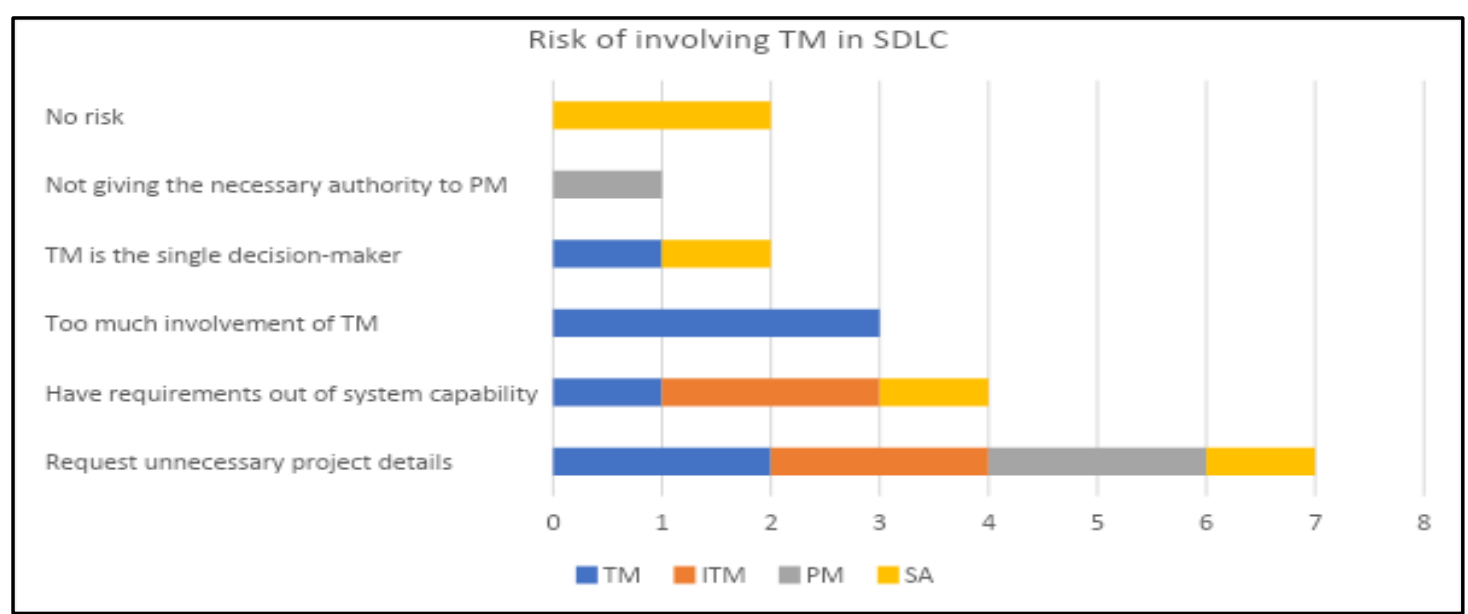

Figure 4: Risk of involving TM in SDLC

with 1 TM, 2 ITM, 0 PM, and 1 SA), (3) too much involvement of $\mathrm{TM}(\mathrm{N}=3$, with $3 \mathrm{TM}, 0 \mathrm{ITM}, 0 \mathrm{PM}$, and 0 $\mathrm{SA})$, (4) TM is the single decision-maker ( $\mathrm{N}=2$, with $1 \mathrm{TM}, 0$ ITM, 0 PM, and $1 \mathrm{SA}$ ), (5) not giving the necessary authority to PM ( $=1$, with 0 TM, 0 ITM, 1 PM, and $0 \mathrm{SA})$, and (6) no risk $(\mathrm{N}=2$, with $0 \mathrm{TM}, 0 \mathrm{ITM}, 0 \mathrm{PM}$, and $2 \mathrm{SA})$.

The top two factors that might put a project into risk and delay the progress of project are (1) when TM wants "to know everything in details [regarding the new system or the project]" or "to understand every process of the new system in depth" during the SDLC, and (2) make requests that are "out of the scope of the system". This view point was supported by the TM, ITM, PM, and SA. For example, an ITM stated: "When the CEO tries to interfere with IT people's work by asking them to know the system implemented in detail, or when he insists on implementing one of his requirements that is out of system capability, then he might delay our work and create some risks for the project.".

The third factor that may put a project in risk is too much involvement of TM in the SDLC. Although it is considered beneficial to have TM in the SDLC, too much involvement of

TM in the SDLC could be problematic.

Interestingly, this view point was only mentioned by the TM, and none of the employees (i.e., ITM, PM, and SA) considered this as an issue. In general, TM seemed to believe that "too much involvement of top managers in the IT project is not always a good thing" and at times "it can also be perceived as a barrier". Furthermore, the amount of involvement of TM may depends on "expertise and experience". A TM provided an example to explain: "For example, if the product is very technical it no longer relies on my [TM] support for its success. In this situation, I [TM] will lack the professional skills required to correctly assess the situation.'

The fourth risk factor is when TM being a single decision maker. TM acting as a single decision maker during SDLC could pose negative impact on the IT project. In this case, the TM may "not agree with what all departments want", may "try to enforce something in the system that runs contrary to the company procedure", or may require the project team to "take his approval even for a small decision". If TM is a single decision maker during SDLC, he may "cause delay of the project" or "make the wrong decisions that will impact the whole project", as he may be unwilling to listen to other employees.

The fifth risk factor is TM not giving the necessary authority to PM, which was mentioned by a PM during the interview. The PM stated: "Not giving the project manager the authority to carry out the project and trying to interfere with some of the PM decisions, for example, having to go through various decision-making processes to get approval for spending a small amount of money.". Finally, it was worth mentioning that 2 SA believed that "there is no risk in involving the TM in $S D L C$ " as the TM was always "cooperative and supportive".

\subsection{Theme 5: Knowledge TM should have prior to participate in SDLC}

This theme presents knowledge TM should have prior to participate in SDLC. When considering risk involving TM in the SDLC may cause, one thing that needs to be considered is the IT knowledge the TM has, as a PM indicated "It [risk] depends on their [TM] awareness of IT technology. If they [TM] don't [have the proper IT knowledge], it might be risky.". All interview participants believed that if TM should have "some technical knowledge", it will help them "understand the IT jargon", "interact better with IT people", and "understand the SDLC", and hence can participate in the SDLC more efficiently. Lack of technology may pose some risk to the project, for example, "If the top management doesn't have the technical background, they might ask for something the system can't do, and if they insist on it then a problem will be escalated 
to the project team." as indicated by a TM.

However, although it is preferred that TM have some technical knowledge, "it's not a necessity". Besides, as an SA pointed out that "it is the responsibility of IT people to explain to TM how the system will benefit the company without going into technical terms". TM should think strategically and leave all the technical parts to the IT department. In other words, as a TM stated: "TM should explain its business requirements and tell IT people what the system should do and

leave the technical requirements to IT staff.". A PM's statement also reflects this point of view:

"It is better if the top management has some technical knowledge that will help a lot to understand the project manager when explaining the project plan and timeframe. However, I think it is better for TM to know more about the company's business strategy and to have a good understanding of the business and output they expect from the system, so they don't have to be technologically savvy."

\subsection{Theme 6: Information TM need to know before agreeing on a IT system}

This Theme is about information TM would like to know in SDLC. When there is a need for a new system to be implemented in an organization, there is

some key information TM that need to know about the system as depicted in figure 5, including (1) budget and resources needed for the project $(\mathrm{N}=16$, with $4 \mathrm{TM}, 3 \mathrm{ITM}, 4 \mathrm{PM}$, and 5 SA), (2) benefits of the system to the company ( $\mathrm{N}=14$, with 5 TM, 2 ITM, 3 PM, and 4 SA), (3) timeframe for the project (N = 10, with 0 TM, 2 ITM, 3 PM, and $5 \mathrm{SA}$ ), (4) functionality of the system $(\mathrm{N}=9$, with $4 \mathrm{TM}, 2 \mathrm{ITM}, 2 \mathrm{PM}$, and $1 \mathrm{SA}),(5)$ if the system aligns with company goals $(\mathrm{N}=9$, with $2 \mathrm{TM}$,

1 ITM, $5 \mathrm{PM}$, and $2 \mathrm{SA})$, (6) how to execute the system $(\mathrm{N}=3$, with 3 TM, 0 ITM, 0 PM, and 0 SA), and (7) changes associated with the new system $(\mathrm{N}=2$, with $0 \mathrm{TM}, 2$ ITM, 0 $\mathrm{PM}$
0 SA)

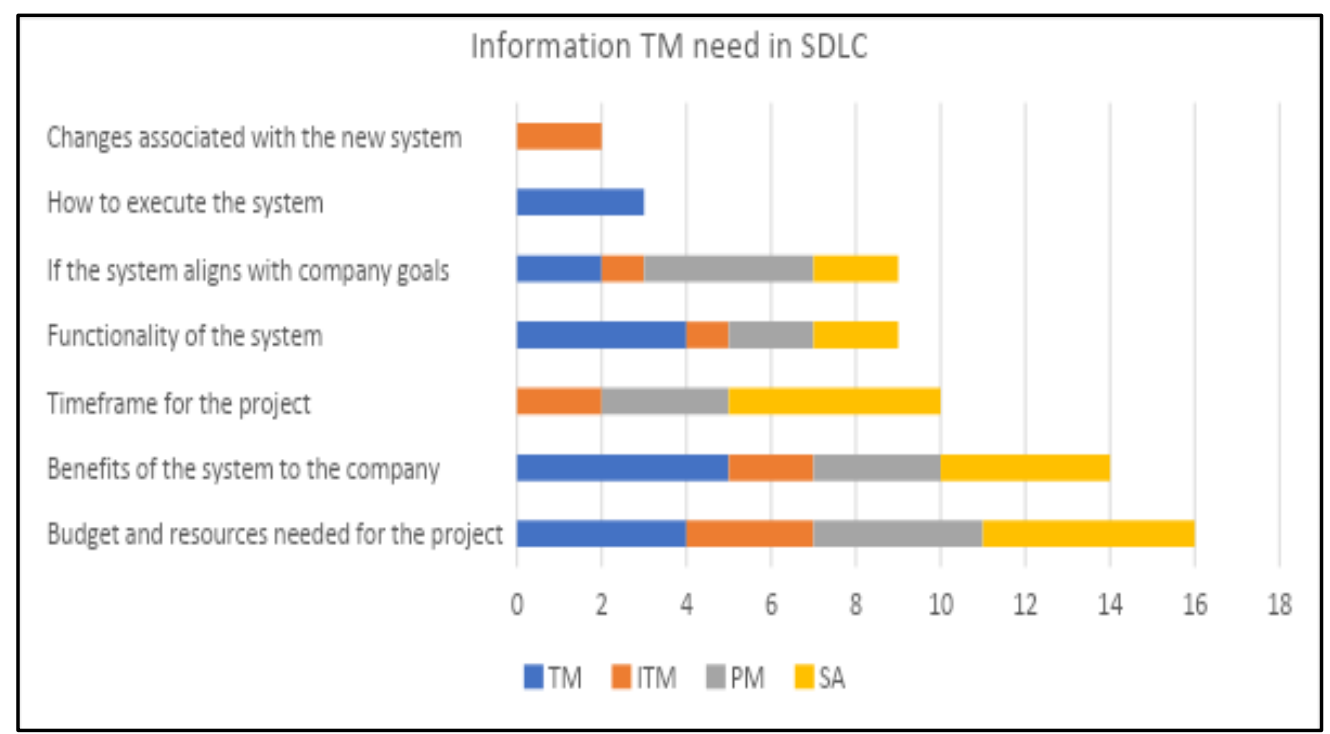

Figure 5: Information TM need in SDLC

When evaluating a new system, "First, they [TM] need to know the cost of the system.", said a PM. "They [TM] need to know what budget is required to implement the new system, [and] what resources are needed internally." because "TM need to make decisions [regarding the new system] that impact the entire organization, [and] hence, they need high-level data with the ability to drill down when necessary to find the required details.", suggested by an ITM.

Second, TM need to know the organization's benefits of the new system. Forexample, TM would like to know the answers to the following questions:

- "What is the return on investment of the system?" (said by SA),

- "What are the reports that will benefit top management in order to grow the business?" (said a PM),

- "How beneficial the system is to the company to make our operation smooth?" (said a TM), and In general, TM would need to know "how the new system will help reduce the costs and increase the quality of our products, improve our work processes and make our company competitive with similar companies in the marketplace.", as suggested by a TM.

Third, TM need to know "the realistic timeframe for the system". Interestingly, during the interview, none of the TM had mentioned the need of knowing the timeframe of the project, while all $5 \mathrm{SA}$ had indicated that timeframe of the project may be key information to TM in SDLC. This may reflect the fact that even though TM are OK with overtime, employees may still worry about requesting overtime or an extension of the deadline.

Fourth, TM would need to know the functionality of the new system and "the system's ability to cover the company's processes". For example, TM may want to evaluate the functionality of the new system based on the answers of the following questions:

- "What kind of reports the system will produce for them [TM]?" (said an ITM),

- "Whether the system can safely and securely handle patient data?" (said an ITM),

- "Is the system flexible and can track KPI's?" 
(said a PM),

- "Is the system easy to operate and provide all the necessary reports?" (said a TM),

- "What are the reports that will help top management in order to develop the business?" (said an SA), and

- "What reports I [TM] can extract from the system?" (said a TM).

Fifth, during SDLC, TM definitely want to know if the new system aligned with strategies/goals/objectives for the organization, as an SA indicated: "[During SDLC], They [TM] want to know if the system is aligned with the business plan of the organization.". The key issue is to ensure that the project is aligned with the organization's goals and objectives, as a TM emphasized: "Each department must prepare its objectives and action plans to be discussed and approved at our meeting. ... I [TM] must ensure that their plans are aligned with the business strategy of the organization and for the benefit of the company as a whole.".

Finally, noted that three TM indicated that they also like to know "what is the appropriate way to execute the system" and two ITM suggested that TM might want to know "what procedures and policies the new system needs to modify" within the organization.

\subsection{Theme 7: Barriers for TM to participate in SDLC}

This Theme discussed various barriers that prevent TM from participating in SDLC as depicted in figure 6. Interview participants suggested several barriers that may prevent TM from participating in SDLC, including (1) busy schedule ( $\mathrm{N}=16$, with $5 \mathrm{TM}, 5 \mathrm{ITM}, 3 \mathrm{PM}$, and $3 \mathrm{SA})$, (2) not convinced by the new system ( $\mathrm{N}=13$, with $5 \mathrm{TM}, 4$ ITM, 2 PM, and 2 SA), (3) do not understand the project / lack of IT knowledge ( $\mathrm{N}=10$, with 4 TM, 3 ITM, 3 PM, and 0 SA), (4) lack of regular communication $(\mathrm{N}=3$, with $0 \mathrm{TM}, 3$ ITM, 0 $\mathrm{PM}$, and $0 \mathrm{SA}),(5)$ unclear role for $\mathrm{TM}(\mathrm{N}=1$, with $0 \mathrm{TM}, 1$ ITM, 0 PM, and 0 SA), and (6) not involved from the beginning ( $\mathrm{N}=1$, with 0 TM, 0 ITM, $1 \mathrm{PM}$, and $0 \mathrm{SA}$ ).

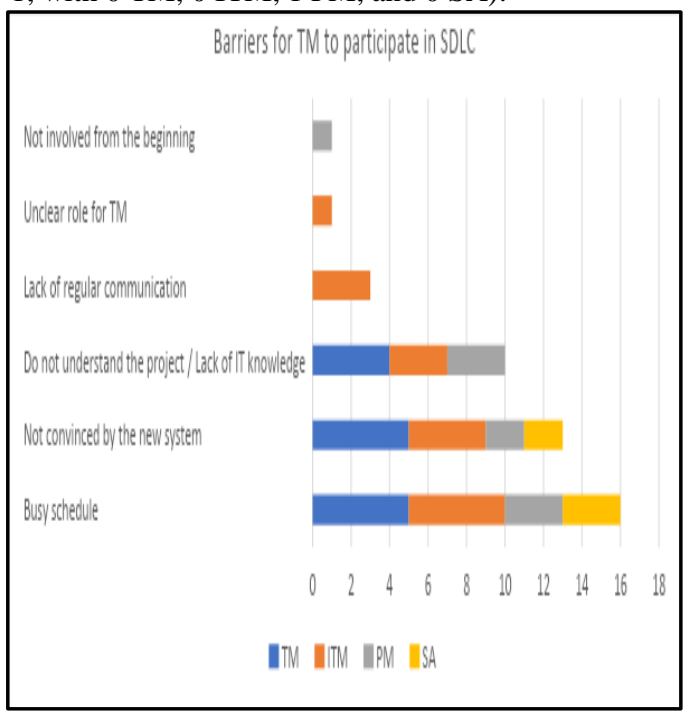

Figure 6: Barriers for TM to participate in SDLC
During the SDLC, TM may start with project and then suddenly stopped or lost interest in the project during the implementation of the system. Interview participants have proposed several reasons for TM lack of participation in the SDLC. One of the main reasons is that the TM has "a very busy schedule". For example, "TM is always busy and travelling most of the time then they would lose interest of the project because they're away from the project for a long time", said by an ITM. When the TM has a busy schedule, he/she would be "too busy to get involved [in the SDLC]". A TM suggested "TMs are usually very busy people so you need to choose the right time to engage them in the project."

TM will also be reluctant to participate in the SDLC if they are "not convinced by the new system" after IT people clearly explain the function/benefits of the system to the TM and TM knows how the new system works. If "they [TM] do not personally see the value of the system for them", they will not be satisfied with the new system or know about the benefits of the system, and hence will not be willing to get involved in SDLC.

The other situation that preventing TM from participating in SDLC is "when IT people do not clearly explain the benefits of the new systemto the TM" or when the TM "lack of IT technology". In this case, the TM "doesn't have the right expectations or doesn't understand what's involved in such project". As the TM "do not see the added value of the system from the beginning, so they typically don't want to participate in the implementations until they see the system live then they see the value of the system", suggested by a TM.

Furthermore, due to the lack of IT knowledge and understanding of SDLC, TM "usually hesitate to meet IT people" and "would be more than willing to assign the decision to the IT director [rather than discussing the issues with IT people and making necessary decisions on their own]", mentioned by an ITM and a PM. If TM hesitate to meet IT people, due to their lack of IT knowledge, which may cause them not able to see the added value of the system from the beginning, "so they typically don't want to participate in the implementations until they see the system live then they see the value of the system", concluded by a TM.

Lack of regular communication is another factor that may discourage TM from participating in SDLC. As an ITM said: "I think this [lack of regular communication] could happen when the TM feel neglected and not constantly updated on the project from the project manager. It [lack of regular communication] also could happen when the project manager has no means of contact with TM and can build some tensions between them.".

Other reasons for TM not willing to participate in SDLC including

- unclear role for TM (an ITM stated: "Sometimes TM doesn't realize the effect his presence has on IS system development. Therefore if the project charter does not clarify his roles and duties within the project in depth they usually tend not to participate in the project."), and

- TM "not getting involved in the project from the start" (said a PM).

\subsection{Theme 8: Methods for increasing TM's involvement in SDLC}

This Theme discussed various methods that can increase TM involvement in SDLC. Figure 7 summarized the methods suggested by the interview participants for increasing TM's involvement in SDLC, including (1) project is important and beneficial to the company ( $\mathrm{N}=16$, with $2 \mathrm{TM}, 4$ ITM, 5 
PM, and 5 SA), (2) establish regular communication with TM ( $\mathrm{N}=14$, with 3 TM, 5 ITM, $3 \mathrm{PM}$, and $3 \mathrm{SA}$ ), (3) make good progress on the project $(\mathrm{N}=8$, with $3 \mathrm{TM}, 2 \mathrm{ITM}, 2 \mathrm{PM}$, and 1 $\mathrm{SA})$, (4) involve TM from the beginning ( $\mathrm{N}=7$, with $3 \mathrm{TM}, 1$ ITM, 3 PM, and 0 SA), (5) take TM suggestions seriously ( $\mathrm{N}=$ 5, with 0 TM, 2 ITM, 1 PM, and 2 SA), (6) Clearly identify TM's role/task ( $\mathrm{N}=3$, with $3 \mathrm{TM}, 0 \mathrm{ITM}, 0 \mathrm{PM}$, and $0 \mathrm{SA}),(7)$ project is feasible and tangible $(\mathrm{N}=2$, with $0 \mathrm{TM}, 2$ ITM, 0 $\mathrm{PM}$, and $0 \mathrm{SA})$, and (8) Do not surprise TM with problems $(\mathrm{N}=$ 1, with 0 TM, 1 ITM, 0 PM, and 0 SA).

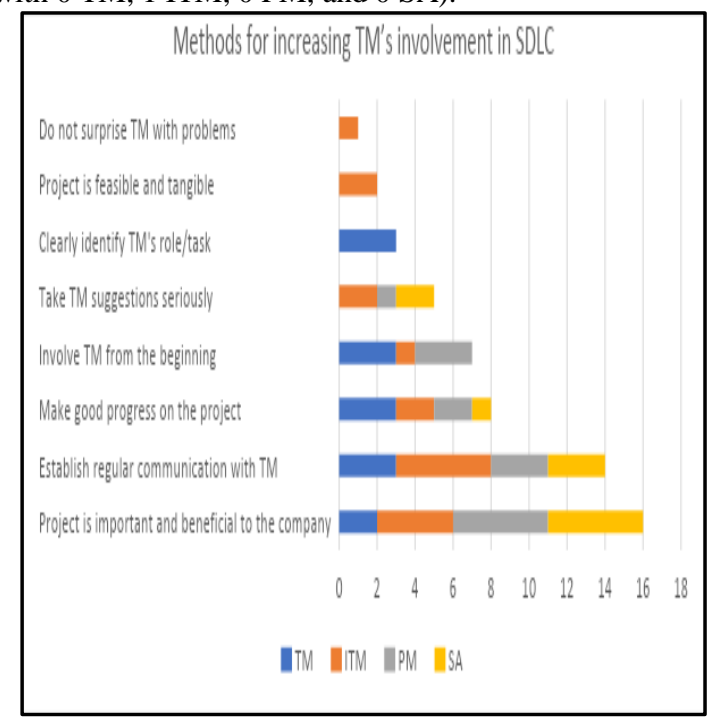

Figure 7: Methods for increasing TM's involvement in SDLC

When the IT project is important and beneficial to the organization, TM will be more than happy to be involved in the SDLC. A TM claimed that

"I usually keep my project continuity depending on how important the new system is to me and to the company.".

In order to show TM the benefits of the system towards the company and the work process, an ITM suggested

"Show them [TM] a sample report of what they can get out of the system, what the system is capable of, or what the actual output is, so they can feel the benefits of the system. ...So, we don't have to tell them [TM] what the system can do technically, but instead we have to show them [TM] how the system can benefit the company and smooth their daily operations".

A PM had a similar opinion: "Through explaining to him [TM] that the new system is capable of delivering all the things he is looking for, in terms of improved reporting, better efficiency of the company's processes and better integration." Ultimately, the purpose of showing TM the new system is so that TM "understand how a system can improve the company's market share and place it in a competitive position; how can the system make his job simpler and more efficient by making report forecasts and campaigns.", according to an SA. By showing TM the benefits of the new system, "they can be better associated with the benefits of the system plus the system progress" as suggested by a PM.

Another way to increase TM's involvement in SDLC is through regular communication with the TM. According to a $\mathrm{TM}$, "an effective feedback mechanism should be put in place to channel any concerns issues between TM and the project team". To encourage TM to continue the participation in SDLC, project team should (1) "keep TM updated on the progress of the project", (2) "show TM the minor or sub milestones of the entire project", (3) "involve him [TM] through timely and short meetings from the start of the project to the end, depending on his/her availability", and, (4) "have a communication plan which provides all the people needed with their contacts included the TM'. A PM emphasized the importance of regular communication between TM and the project team: "You should meet them [TM] at the end of each stage of the SDLC to show what you have accomplished. If you leave them [TM] out of the project for a long time, they [TM] will not be happy with the progress of the project, and they [TM] will have a negative attitude towards it.".

A good progress on the project is also a positive factor that could increase TM's participation in SDLC. An TM clearly claimed: "If the project team show me [TM] that the system is progressing in the right way and what we have planned for is going to be achieved then I [TM] will be welling to continue my work with them and maintain my support to them.". Thus, as an SA pointed out, project team "always try to give them [TM] the good news about the success of implementing the new system", in order to motivate TM to participate in the SDLC.

Involving TM from the beginning of the project makes them feel "they are incorporated in the new project". In other words, as a PM suggested that involving TM from the beginning of the project can "make them [TM] feel that our success is their success and make them [TM] the owner of the system then they will be involved.", which might motivate TM to participate in SDLC more and "to help in implementing the project as what included in the project plan". Furthermore, when involving TM from the beginning of the project, project manager can "define the TM responsibilities in the project charter from the beginning in all phases of the SDLC", which is another positive factor for increasing TM" participation in SDLC. As a TM mentioned, "All the tasks required by the TM should be explained and discussed with them for each phase of the SDLC to know how these tasks can fit within their tight schedule.".

When TM provides feedback about the new system, his/her feedback should be taken "very seriously" and the project team should "give it [the feedback from TM] priority". The project team should also "inform them [TM] that they [suggestions from TM] are incorporated in the new program", which may again make the TM feel "they are incorporated in the new project" and increase their willingness of participating in SDLC.

The last two methods of increasing TM's involvement in SDLC are "do not surprise them with system problems" and proposing a new project that is "not feasible and tangible", as suggested by ITMs. "At the end of the day, they just want to see high-level

reports that help them make strategic decisions". Therefore, "generally they need to see something that is practical and measurable to get them motivated to engage in the SDLC".

\subsection{Theme 9: Efficient work environment to ensure the success of IT projects}

The last theme proposed ways to create an efficient work environment that could ensure the success of IT projects. Figure 8 summarizes participants' suggestions regarding how to establish an efficient work environment to ensure the success of IT projects, including (1) TM - Be supportive $(\mathrm{N}=17$, with 5 TM, 5 ITM, 4 PM, and 3 SA), (2) TM - Provide resources, trainings, and tools $(\mathrm{N}=17$, with $5 \mathrm{TM}, 5 \mathrm{ITM}, 3 \mathrm{PM}$, and 4 SA), (3) TM - Announce the new system and request support 
from all departments $(\mathrm{N}=14$, with $5 \mathrm{TM}, 3$ ITM, 2 PM, and 4 SA), (4) PM - Ensure stakeholders stay on the right track during SDLC ( $\mathrm{N}=10$, with $5 \mathrm{TM}, 2 \mathrm{ITM}, 3 \mathrm{PM}$, and $0 \mathrm{SA}$ ), and (5) TM - Oversee the project (No micromanagement, set strategic goals, etc.) ( $\mathrm{N}=6$, with $3 \mathrm{TM}, 2$ ITM, $1 \mathrm{PM}$, and 0 SA).

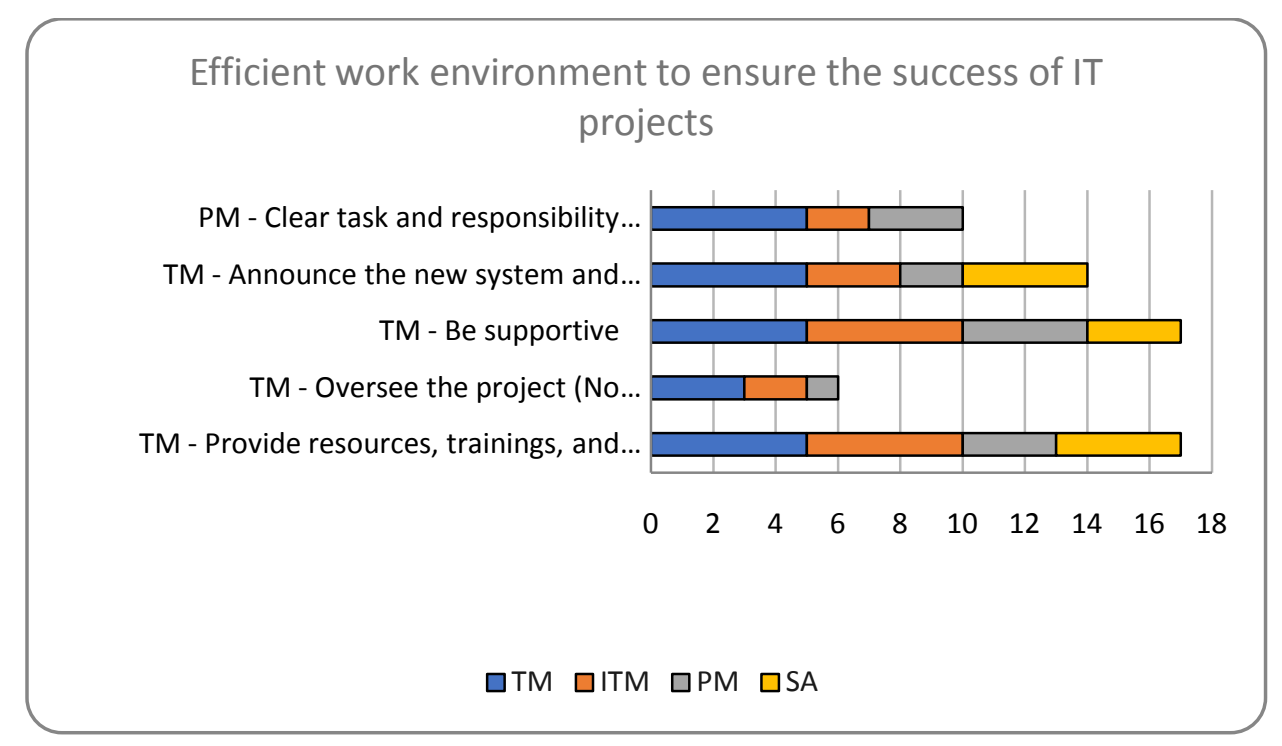

Figure 8: Efficient work environment to ensure the success of IT projects

As an ITM indicated "Through the necessary resources and full TM support for the implementation of a new system, TM can create the right environment". TM can create a right environment for an IT project to operate efficiently and smoothly by providing full support of the team, which may include

- "give support to the project team when the decision had to be taken" (stated by a TM),

- "approving the extra time they [project team] wanted and providing overtime if necessary" (stated by a TM),

- "providing the resources needed or by providing training, promotion" (stated by a TM), and

- "supplying the project with all the required resources and the necessary equipment" (stated by a TM).

As a PM stated, "In order for the project to be successful, TM must guide and support the project at all stages of the SDLC because, with his support, all departments and stakeholders will be eager to participate and use the new system. TM can provide the necessary budget and resources for the project and help to resolve any obstacles or challenges that may arise from users during the project cycle.".

One of the responsibilities of TM is to ensure that project stakeholders stay on the right track through the SDLC process so that the project can progress as planned. To ensure project success, TM needs to "communicate to the company as a whole", "send a letter or memo or email to all stakeholders at the beginning of the project in order to inform them of the value of the system", and "inform all departments that TM is a stakeholder in this project" and all departments need to work with the project team. As an ITM indicated, "This is a reflection of his [TM] support and dedication to the project". A TM further provided his own experience to illustrate the importance of TM announcing the project to the whole organization

"Yes, in the Prime Health Care system, I had to send an email to all department managers to let them know about the importance of the new system to the company. The email explains the benefits of the new system to the company so that they have to cooperate with the project team and let their staff help the project succeed."

Another thing TM could do to ensure an efficient work environment for IT projects is to oversee the whole project. According to a TM, TM should "set strategic goals and strategy and ensure that the project is aligned with them". Also, based on an ITM's opinion, "At the same time, however, the top management will have to follow up on the progress of the project through its meetings with stakeholders in the event of problems that need to be resolved.". A TM further emphasized that "TM should only take action for major issues that come to service during the project, and all small decisions will be left to PM and relevant department managers".

Finally, to help creating an efficient work environment, PM should be in charge of controlling employee involvement during SDLC by doing the following

- "ensure the involvement of the stakeholders and that they stay committed throughout the project" (stated by an ITM),

- "design and develop good and effective reporting mechanism so that all the stakeholders and team members are well informed about the project progress and developments" (stated by a TM),

- "show me [TM] where my involvement is most needed" (stated by a TM).

\section{ANSWERS TO RESEARCH QUESTIONS}

Research Q1 asked: How do TM describe their experiences of participation within the phases of SDLC? All TM believed that involving TM with IT department during the SDLC is essential and they all had all participated in SDLC before. TM participated in SDLC either through meetings or by receiving a weekly and monthly management reports. All TM regarded communication as a very important factor in SDLC and had regular meetings with the project team. Furthermore, TM provided several ways for the IT people to contact them, including email, phone or social media in order to solve any urgent problems and difficulties they face during the implementation of the system. TM believed that they should be 
included in SDLC to (1) approve proposals, and the associated budget and resources, define business requirements and expected functionality for the new system, ensure new system aligns with company strategies, and ensure participations of all stakeholders at the beginning of the project, (2) approve changes of project and resolve issues in the middle of the project, and (3) ensure system acceptance at the end of the project. TM also believed that too much involvement of TM in SDLC may be harmful to the project. All TM thought having some IT knowledge may be a plus in SDLC, though it is not a necessity. During SDLC, TM would like to learn the following information, including budget and resources needed for the project, benefits of the system to the company, functionality of the system, if the system aligns with company goals, and how to execute the system.

Research Q2: How do PM, ITM, and SA describe their experiences of TM's participation within the phases of SDLC? All employees (PM, ITM, and SA) believed that involving TM with IT department during the SDLC is essential. All employees had positive experience working with TM in SDLC. They had described TM as having positive attitude and providing full support in SDLC to help the success of the past project. The employees communicated with TM on a regular basis and when needed (ex: when there were issues of the project or when there are major accomplishment). Employees believed that TM should be included in SDLC to (1) approve proposals, and the associated budget and resources, define business requirements and expected functionality for the new system, ensure new system aligns with company strategies, ensure new system aligns with government requirements, and ensure participations of all stakeholders at the beginning of the project, (2) approve changes of project and resolve issues in the middle of the project, and (3) ensure system acceptance and approve the final product at the end of the project. All employees thought that TM having some IT knowledge may be a plus in SDLC, though it is not a necessity. They believed that TM would like to learn the following information during SDLC, including budget and resources needed for the project, benefits of the system to the company, timeframe for the project, functionality of the system, if the system aligns with company goals, and changes associated with the new system.

Research Q3 asked: How do TM, PM, ITM, and SA describe the challenges and barriers to TM's participation within the phases of SDLC? Interview participants suggested several barriers that may prevent TM from participating in SDLC. TM's busy schedule is the number one barrier to TM's participation within the phases of SDLC. TM may also be reluctant to participate in the SDLC if they are not convinced by the new system after IT people explain the function/benefits of the system. Due to lack of IT knowledge, TM may not understand how the new system works and hence is not willing to participate in SDLC. Lack of regular communication is another factor that may discourage TM from participating in SDLC. In this case, TM may feel neglected and hence lose interest in participating in SDLC. Finally, if TM does not understand what he/she should do during SDLC, then TM may be discouraged to join in the process.

Research Q4 asked: How do TM, PM, ITM, and SA describe the motivation of TM's participation within the phases of SDLC? All participants suggested that motivating TM for participating in SDLC is crucial to project success. A project that is beneficial to the company and establishing regular communication with TM were considered as the two most important factors that can motivate TM to participate in SDLC. TM should be involved from the start of the project so that he or she may be motivated and make good progress.In this case, their role/tasks should be clearly identify, and their suggestions should be taken seriously. Project should be feasible and tangible, and finally, do not surprise TM with system implementation problems.

\section{DISCUSSION}

we categorized our results based on the six stages of SDLC process such as planning, (promoting team and departmental cooperation, providing the necessary resources on time, and committing all stakeholders to the project) analysis (participation in requirements elicitation, negotiation and prioritization of requirements) designing, (review of prototypes, providing feedback about the development processes, attending stand-ups and project meetings), implementation, (User Acceptance Testing, training, raising change requests, attending the post-implementation review meetings and to resolve outstanding issues). Post implementation (testing and finally maintenance, during implementation, post implementation and post installation ( 1 year after the users have been using the system). We first give a brief overview of top management involvement and the turn of events over the course of the project based on these 6 stages:

The primary benefit of utilizing SDLC is the control it offers over the development process. It aids in ensuring that the system meets all of the requirements. As a result of this study, we believe that the involvement and support of top management will stimulate all stakeholders to participate and be more involved and creative during the SDLC phases.

The results of this study reaffirmed the significant and substantial effect of top management support on the success of projects for IS development. Participants interviewed highly praised TMs' positive attitudes about getting involved in most of SDLC phases. As pointed out by the study participants, there are several activities TM needs to be aware of in order to be involved and supportive throughout the SDLC phases.

\subsection{Planning phase}

This is the initial phase of SDLC.Research shows that the planning decision occurs at the organizational upper level, and usually without much lower-level participation (Jasperson et al, 2005). According to the perspectives of our study participants, top management is familiar with the organization's current business activities. As a result, their guidance, motivation, and inspiration are necessary to aid the project team in properly establishing what the system needs to do for the organization throughout the SDLC. At this stage TM can demonstrate leadership by recognizing the strategic importance of the new system and subsequently allocating time and money for proper system employment.This is consistent with (Elzamly et al., 2016 and Madampe, 2017), who noted that during the planning phase, Top or senior management is required to assist the project team in determining what the system needs to perform for the business. In addition, obtaining top management approval and support can increase the chances of a successful implementation because top management support can assure the needed resources and funding for provided an effective system implementation. When the IT project is initiated and supported by TM, there is a higher chance of success, based on a TM's experience. This is because when employees realize that the project is being supported by TM, they will all be more supportive and dedicated. This also supported by (Boonstra 2013; Darma et al., 2018; Eian et al., 2020). The planning phase would establish project goals and a high-level strategy for the project plan. By definition, planning is a crucial organizational process. The planning stage's major deliverables are a general issue description, team members roles responsibilities, and a feasibility report. 
Based on this study, the most important phase of SDLC to involve TM is the project planning phase, where TM can participate in the following actions:

(1) Understanding the aim of the project in order to Approving proposals, and the associated budget and resources,

(2) Make the project important to everyone.

(3) Providing the required authority to begin the project by assuring enough staffing in the software project with clearly defined roles and duties in accordance with the project objectives, so that the project team is competent and has the skills to fulfill their duties effectively.

(4) Defining the new system's business requirements and projected functionality,

(5) Ensuring new system alignment with company strategies,

(6) Ensuring new system aligns with government requirements,

(7) Ensuring participations of all needed stakeholders

(8) Defining and communicating responsibility and authority for all stakeholders

\subsection{Analysis Phase}

Acquiring business needs is crucial at this stage of the SDLC. A business requirement is a succinct list of business functions that the system must provide in order to be effective. According to the findings of this study, TM engagement can assist in the approval of modifications and the resolution of concerns. Difficulties in gaining shared understanding of requirements for the project of IS development may cause conflicts between departments and team members, rework, and increases the chance of delays in product delivery this is in line with (Menezes et al., 2019; Pasha et al., 2018; Rupaliya et al., 2016). The key deliverables of the analysis stage are formal requirements document and modelling of current system. In addition, modifications and associated issues that might jeopardize the project's performance should be recognized, analyzed by project team members, and either authorized, denied, or delayed by the TM. This is supported by (Islam \& Evans, 2020). Based on this study, the main activities TM can participate in the following actions:

(1) Use their authorities to force department managers and employees to participate in the business requirements gathering process,

(2) Approve changes and resolve requirements issues,

(3) Approve changes and the associated issues that could affect the success of the project,

(4) Coordinate and manage business requirement between departments,

(5) Make sure that the company strategic requirements and the department requirements will be clear to the project team, and

(6) make sure the objectives of the organization are implemented.

\subsection{Design Phase}

In this phase, continuous discussion on requirements among relevant stakeholders is needed to gain a unified interpretation and understanding of the objectives of the system development project and the system requirements, which will in turn optimize the designs of the project and formalize acceptance of the completed project deliverables (Islam \& Evans, 2020; Jain $\&$ Suman, 2015). The design stage's major deliverables are a functional specification document, a technical specification document, and an implementation timetable.Based on this study, the main activities TM can participate in will be limited to:

(1) Reviewing and then approving the System Design Document with the System analyst and Project Manager.

(2) Ensuring the quality of the output of design activities that fall within the project scope.

\subsection{Implementation Phase}

The study reaffirm that TM should be involved during not only the planning and design phases of SDLC, but also the implementation phase (i.e., at the end of the project), as involving TM can help ensure system acceptance among users.The essential implementation deliverables are a fully installed system, fully trained users, and user and operational manuals. As pointed out in the study, although TM and the project team often meet on a regular basis, there may be issues that need to be resolved urgently or overcome during the implementation of the system. Indeed, TM need to be involved to help resolve any obstacles or challenges that may arise during the project cycle this in line with (Elzamly et al., 2019; Eian et al., 2020; Aldahmash, 2018; Yunus et al., 2019). Based on this study, the main activities TM can participate in are:

(1) Support the implementation process and assure the availability of all the different departments and teams participating across the organization.

(2) Check with the project team if the initial set of requirements and the expectations are met, and

(3) Check with the project team that all the system capabilities requested by stakeholders are included, and all the reports requested as well.

(4) Approves project deliverables such as the Completed System, System Documentation, and Implementation Notice (along with the Project Manager).

(5) Review and approves the Post-Implementation Review Report in collaboration with the Project Sponsor, Project Manager, and Development Team.

(6) Ensure system integration, user acceptance testing (UAT) and quality assurance.

Based on the results of this study, top management engagement in the post implementation stage is required. This will guarantee that the solution has a high user acceptance rate, that deadlines are fulfilled, and that the transition is smooth throughout the project. As pointed out by this study, Top management's commitment and participation strongly influence organizational culture which in turn impacts employee's attitudes towards use of information system development practices, this in line with (Maher et al., 2020). The motivation and support shown by top management will not only influence effectiveness and efficiency among workers but also enables greater acceptance of information technology innovation. Therefore, when there is resistance against adopting development practices for information system development, it is then the TM's responsibility to set policy enforcement and perform monitoring role to implement policies to ensure employees adopt and benefit from the IS installed.

\subsection{Testing and Maintenance Phase}

Based on this study nothing was mentioned about the role and participation of top management in these two phase. As a result, TM's involvement will be restricted to resolving any difficulties or obstacles that arise during these stages.

According to the research above, the most critical phases of the 
SDLC in which TM should be involved are the project planning and implementation stages. Sometimes they are required in other phases as well. TM should be active in all stages of the project in case there are many variances impacting the organization as a whole that demand TM's attention. TM should also take action on important issues that arise throughout the course of the project, but all minor issues should be left for a lower management and appropriate department managers.

\subsection{Risk in Involving TM}

Although involving TM in SDLC has many benefits, there are also risks of doing so. This study shows that when TM request unnecessary project details and try to know the IS innovation in details or try understand every process of the new system development in depth, it might put a project into risk and delay the progress of project. TM should perform governance and leadership for the project and support the project manager and the project team as it is mentioned in (Elzamly et al., 2016; Liu et al., 2015). TM should refrain themselves from micromanaging the project this is in line with (Menezes et al., 2019; Wagner, 2018). Micromanagement and excessive oversight is when a supervisor not only examines but also nitpicks everything, from the tiniest tasks to day-to-day procedures (Dhingra, 2015). A manager who micromanager may stand over employees' shoulders while they work as was mentioned by one of the interviewers. Positive recognition and appreciation go much further than micromanagement, which results in a lack of trust and may interfere with progress of the project (Jain \& Suman, 2015; Niazi, Babar, \& Verner; 2010).

The other risk of involving TM in the SDLC is when they make requests that are out of the scope of the system. Having undeliverable/unrealistic scope and objectives/goals is a critical risk factor leading to the failure of the information system development project (Bilal et al., 2020; Elzamlyet al., 2019; Menezes et al., 2019; Pasha et al., 2018). Undeliverable/unrealistic scope and objectives/goals in the software development process may be introduced with the knowledge misunderstand by project management this is in line with (Elzamlyet al., 2019). It may lead to changes in the software requirements, add extra cost, and extend the delivery timeframe (Elzamlyet al., 2019). Although one cannot get rid of risks in information system development projects completely, the likelihood of risk occurrence (ex: undeliverable/unrealistic scope and objectives/goals) can be reduced along with its impact by incorporating proper management techniques (Bilal et al., 2020). For example, Continuous requirement discussion among key stakeholders is required to achieve a unified interpretation and knowledge of the IS development project's objectives and system requirements, which will in turn optimize project designs and formalize acceptance of final project deliverables. Top management should tailor the relevant and realistic goals of information system development project to operational level (Khan \& Keung, 2016; Ramasubbu, 2013).

\subsection{TM barriers to Involvement}

The study identified several barriers for TM to participate in SDLC, with the number one barrier being busy schedule of TM. Top management support refers to the willingness of top manager in providing the resources needed to operate the IS implementation successfully (Darma et al., 2018). According to the interview results, TM were willing to provide the support needed in SDLC; however, due to their busy schedule, TM may be under time pressure for providing the necessary support This finding largely aligned with past research where operational management indicated that time pressure was a preeminent hurdle to process improvement execution (Eian et al., 2020; Khan \& Keung, 2016; Niazi et al., 2010). Under time pressure, TM may make decisions in order to stay on schedule; however, those decisions may not be in the interest of the IS development projects.

The other two barriers for TM to participate in SDLC identified in this study were TM not convinced by the new system, and TM not understanding the project or not understanding the value of the new system to the organization. Ineffective communication or language barriers in software project communications (Elzamly et al., 2019) and lack of adequate technical knowledge (Khan \& Keung, 2016) may attribute to TM not convinced by the new system and/or not understanding the project. According to van Kelle et al. (2015), TM's belief in the value created by the information system development project is essential to the project success. Therefore, through effective communication, project team members should make every effort to help TM understand the potential and value the IS innovation project provide to the organization (Kanavittaya, 2016; Pasha et al., 2018; Rupaliya et al., 2016).

\subsection{TM motivation}

Although many studies have suggested that TM support during SDLC is crucial to project success, no research has provided guidelines for how to increase TM's participation in SDLC (Young \& Jordan, 2008). This study proposed several methods for motivating TM to join in SDLC, including (1) project is important and beneficial to the company, (2) establish regular communication with TM, (3) make good progress on the project, (4) involve TM from the beginning, (5) take TM suggestions seriously, (6) clearly identify TM's role/task, (7) project should be feasible and tangible, and (8) do not surprise TM with system implementation problems. These suggestions are consistent with the best practice solutions proposed in Jain and Suman (2015) and Nisyak et al. (2020) to address humanrelated SDLC challenges. Among the methods proposed to motivate TM to join in SDLC, proposing a project that is beneficial to the company and establishing regular communication with TM were considered as the two most important factors by the interview participants in this study. TM make long-term decisions affecting an organization's internal policies, operational procedures, and core objectives (Barrick, Thurgood, Smith, \&Courtright, 2015; Haynie et al., 2016; Kanavittaya, 2016). As such, according to the results of this study, during SDLC, there is some key information TM need to know before agreeing on the new system, including (1) budget and resources needed for the project, (2) benefits of the system to the company, (3) timeframe for the project, (4) functionality of the system, (5) if the system aligns with company goals, (6) how to execute the system, and (7) changes associated with the new system. TM evaluate the potential values the IS development project can provide to the organization based on the information they learned in SDLC. As TM sees an overall picture and the business strategies of the organization, if they deem the IS development project will not be beneficial to the organization, they will not be motivated to join in SDLC.

\subsection{Project team communication with TM}

TM need to understand the potential benefits of the IS development project for the organization, and how their roles in achieving strategic alignment. Therefore, it is critical for the project team to communicate what is happening, including the scope, objectives, and activities of the project with the TM. This in line with (Eian et al., 2020; Garousi et al., 2019; Gondal et al., 2018; Nisyak et al., 2020). Communication has been widely recognized as an important component of teamwork. 
Communication provides the avenue to exchange information, share ideas among team members, coordinate efforts and provide feedback (Ibrahim et al., 2018). Limited interactions between project team and TM may lead to misinterpreted and distorted information, reduce awareness about project activities, and negatively affect commitment establishment (Jain \& Suman, 2015). Thus, through effective communication process, project team ensure timely and appropriate disposition of project information to be delivered to TM, which will help TM monitor project progress regularly and keep TM engaged throughout the project. Continuous discussion on project activities and requirements among relevant stakeholders (ex: TM and project developers) is needed to gain a unified interpretation and understanding, and will enhance trust and keep up motivation for all stakeholders this is in line with (Jain \& Suman, 2015).

\section{CONCLUSION}

According to the findings of this study, TM assistance and engagement should be included in the scope of an IS project team. The team can specifically request such help by interacting with Top management and requesting that he or she be informed of the engagement from the beginning. As top management is expected to engage more to the IS project, they become increasingly committed to and supportive of the project over time.This strategy challenges the conventional way of engaging TM through rational reasoning. The most important phases of the SDLC in which TM should be involved in are the project planning phase and the post implementation phase. Sometimes in other phases as well when decisions are needed.This study explores the role of top management in the various stages of SDLC, which will enable us in understanding the support mechanism from top management at each level. Furthermore, the authors provide approaches for inspiring Top management to engage in the SDLC, as well as hurdles that prevent them from doing so.This paper has certain limitations. To begin, our findings stem from a single project location. More research is needed to see whether our findings are applicable to other situations. Second, because we used a standard SDLC, our research indicates nothing regarding the relationship between TMS and project success. Significant research has already shown a link between TMS and success.

\section{REFERENCES}

[1] Akgun, A. E., Keskin, H., Ayar, H., \&Okunakol, Z. (2017). Knowledge sharing barriers in software development teams: A multiple case study in Turkey. Kybernetes. pp, 566-644.

[2] Aldahmash, A. M. (2018). A review on the critical success factors of agile software development: an empirical study [Doctoral dissertation, University of Southampton]. University of Southampton Research Repository.

[3] Anney, V. N. (2014). Ensuring the quality of the findings of qualitative research: Looking at trustworthiness criteria. Journal of Emerging Trends in Educational Research and Policy Studies, 5(2), 272-281.

[4] Antony, J., \& Gupta, S. (2019). Top ten reasons for process improvement project failures. International Journal of Lean Six Sigma.

[5] Barrick, M. R., Thurgood, G. R., Smith, T. A., \&Courtright, S. H. (2015). Collective organizational engagement: Linking motivational antecedents, strategic implementation, and firm performance. Academy of Management journal, 58(1), 111-135.

[6] Ben Rehouma, M. (2020). Exploring the Role of
Participation in Government Employees' Adoption of IT: A Qualitative Study of Employees' Participation in the Introduction of the E-File in Germany. International Journal of Public Administration in the Digital Age (IJPADA), 7(1), 33-46. doi:10.4018/IJPADA.2020010103.

[7] Bilal, M., Gani, A., Liaqat, M., Bashir, N., \& Malik, N. (2020). Risk assessment across life cycle phases for small and medium software projects. Journal of Engineering Science and Technology, 15(1), 572-588.

[8] Birt, L., Scott, S., Cavers, D., Campbell, C., \& Walter, F. (2016). Member checking: a tool to enhance trustworthiness or merely a nod to validation?. Qualitative health research, 26(13), 1802-1811.

[9] Boonstra, A. (2013). How do top managers support strategic information system projects and why do they sometimes withhold this support. International Journal of Project Management, 31, 498-512.

[10] Bourque, P., \& Fairley, R. E., eds.,(2014) Guide to the Software Engineering Body of Knowledge (SWEBOK (R)): Version 3.0, IEEE Computer Society; www.swebok.org.

[11] Braun, V., \& Clarke, V. (2006). Using thematic analysis in psychology. Qualitative Research in Psychology, 3, 77101

[12] Campbell, J. L., Quincy, C., Osserman, J., \& Pedersen, O K. (2013). Coding in-depth semi- structured interviews: Problems of unitization and intercoder reliability and agreement. Sociological Methods \& Research, 42(3), 294320.

[13] Carpenter, M. A., Geletkanycz, M. A., \& Sanders, W. G. (2004). Upper echelons research revisited: Antecedents, elements, and consequences of top management team composition. Journal of Management, 30(6), 749-778.

[14] Cicmil, S. and Hodgson, D. (2006) New possibilities for project management theory: a critical engagement, Project Management Journal, 37(3), 111-122.

[15] Collier, N., Fishwick. F., Floyd, w. (2004). Managerial involvement and perceptions of strategyprocess, Long Range Planning, 2004, 37, 67-83.

[16] Darma, J., Susanto, A., Mulyani, S., \&Suprijadi, J. (2018). The Role of Top Management Support in the Quality of Financial Accounting Information Systems. Journal of Applied Economic Sciences, 13(4).

[17] de Sousa Jabbour, A. B. L., Jabbour, C. J. C., Foropon, C., \&GodinhoFilho, M. (2018). When titans meet-Can industry 4.0 revolutionise the environmentally-sustainable manufacturing wave? The role of critical success factors. Technological Forecasting and Social Change, 132, 18-25.

[18] Denis, D. R. and D. K. Denis (1995). Performance Changes Following Top Management Dismissals, Journal of Finance, 50, 1029-1057.

[19] Dhingra, G. (2015). Micromanagement-boon or bane. An employee's perception-with reference to IT Sector. Int. J. Res. Manag. Soc. Sci, 3(1), 38-42.

[20] Dong, L., Neufeld, D., \& Higgins, C. (2009). Top management support of enterprise systems implementations. Journal of Information Technology, 24, $55-80$

[21] Eian, I. C., Yong, L. K., Li, M. Y. X., \&Hasmaddi, N. A. B. N. (2020). Integration of Security Modules in Software 
Development Lifecycle Phases. arXiv preprint arXiv:2012.05540.

[22] Elbanna, A. (2013). Top management support in multipleproject environments: An in practice view. European Journal of Information Systems, 16(1), 1-17.

[23] Elzamly, A., Hussin, B., \&Salleh, N. (2016). Top fifty software risk factors and the best thirty risk management techniques in software development lifecycle for successful software projects. International Journal of Hybrid Information Technology, 9(6), 11-32.

[24] Elzamly, A., Messabia, N., Doheir, M., Abu-Naser, S. S., Yaacob, N. B. M., Al-Aqqad, M., \&Alazzam, M. (2019). Assessment risks for managing software planning processes in information technology systems. International Journal of Advanced Science and Technology, 28(1), 327 338.

[25] Fitriani, W. R., Rahayu, P., \&Sensuse, D. I. (2016). Challenges in agile software development: A systematic literature review. In 2016 International Conference on Advanced Computer Science and Information Systems (ICACSIS) (pp. 155-164). IEEE.

[26] Garousi, V., Tarhan, A., Pfahl, D., Coşkunçay, A., \&Demirörs, O. (2019). Correlation of critical success factors with success of software projects: an empirical investigation. Software Quality Journal, 27(1), 429-493.

[27] Geyskens, I., Steenkamp, J.-B., Scheer, L.K. and Kumar, N. (1996), "The effects of trust and interdependence on relationship commitment: a transatlantic study", International Journal of Research in Marketing, Vol. 13 No. 4, pp. 303-317.

[28] Gondal, H. A. H., Din, S. M. U., Fayyaz, S., Zeb, M. D., \& Nadeem, B. (2018). Preeminent risk factor affecting software development. In 2018 International Conference on Advancements in Computational Sciences (ICACS) (pp. 1-7). IEEE.

[29] Griffin, R. \& Moorhead, G. (2014). Organizational Behavior: Managing People and Organizations, 11th Edition. Arizona State University: Cengage.

[30] Haynie, J. J., Mossholder, K. W., \& Harris, S. G. (2016). Justice and job engagement: The role of senior management trust. Journal of Organizational Behavior, 37(6), 889-910.

[31] Hertati, L., Widiyanti. M. Desfitrina., \&Syafarudin.A. (2020). The Effects Of Economic Crisis On Business Finance. International Journal of Economics and Financial Issues 10, (3) 236-244.

[32] Hoda, R., \&Murugesan, L. K. (2016). Multi-level agile project management challenges: A self-organizing team perspective. Journal of Systems and Software, 117, 245257.

[33] Hooley, G., Lynch, J. and Shepherd, J. (1990), "The marketing concept: putting the theory into practice", European Journal of Marketing, Vol. 24 No. 9, pp. 7-23.

[34] Hsia, T. L., Chiang, A. J., Wu, J. H., Teng, N. N., \& Rubin, A. D. (2019). What drives E-Health usage? Integrated institutional forces and top management perspectives. Computers in Human Behavior, 97, 260-270.

[35] Hsu, H. Y., Liu, F. H., Tsou, H. T., \& Chen, L. J. (2019). Openness of technology adoption, top management support and service innovation: a social innovation perspective. Journal of Business \& Industrial Marketing.

[36] Ibrahim, Z., Johar, M. G. M., \& Rahman, N. R. A. (2018) The Quality of Teamwork on Methodology in Software Development Workflow. International Journal of Engineering \& Technology, 7(4.28), 510-525.

[37] Islam, S., \& Evans, N. (2020). Key Success Factors of PRINCE2 Project Management Method in Software Development Project: KSF of PRINCE2 in SDLC. International Journal of Engineering Materials and Manufacture, 5(3), 76-84.

[38] Jain, R., \& Suman, U. (2015). A systematic literature review on global software development life cycle. ACM SIGSOFT Software Engineering Notes, 40(2), 1-14.

[39] Jaworski, B.J. and Kohli, A.K. (1993), "Market orientation: antecedents and consequences", Journal of Marketing, Vol. 57, pp. 53-70.

[40] Kalliamvakou, E., Bird C., Zimmermann T., Begel, A., DeLine R., and German D. M.,. (2019) "What Makes a Great Manager of Software Engineers?" IEEE Transactions on Software Engineering, 45(1), 87-106.

[41] Kanavittaya, P. (2016). The alignment of business strategy and IT/IS strategy, where agile software development is applied (Doctoral dissertation, Murdoch University).

[42] Ke, W., and Wei, KK. (2008) Organizational culture and leadership in ERP implementation. Decision Support Systems 45(2), 208-218.

[43] Kearns, G. (2007). How the internal environment impacts information systems project success: an investigation of exploitative and explorative firms, Journal of computer information systems, Fall 2007, 48(1), 63-75.

[44] Khan, A. A., \& Keung, J. (2016). Systematic review of success factors and barriers for software process improvement in global software development. IET software, 10(5), 125-135.

[45] Koch, T. (2006). Establishing rigour in qualitative research: The decision trail. Journal of Advanced Nursing, $53,91-100$

[46] Licorish, S. A., \&MacDonell, S. G. (2017). Exploring software developers' work practices: Task differences, participation, engagement, and speed of task resolution. Information \& Management, 54(3), 364-382.

[47] Lincoln, Y.S., \& Guba, E.G. (1985). Naturalistic inquiry. Newbury Park, CA: Sage.

[48] Liu, G. H., Wang, E. T., \& Chua, C. E. (2015). Leveraging social capital to obtain top management support in complex, cross-functional IT projects. Journal of the Association of Information Systems, 16(8), 707-737.

[49] Madampe, K. (2017). Successful Adoption of Agile Project Management in Software Development Industry. International Journal of Computer Science and Information Technology Research,(November 2017).pp. $017-21$.

[50] Maher, Z. A., Shah, A., Chandio, S., Mohadis, H. M., \& Rahim, N. H. B. A. (2020). Challenges and limitations in secure software development adoption-A qualitative analysis in Malaysian software industry prospect. Indian Journal of Science and Technology, 13(26), 2601-2608.

[51] Markus, L.M., Tanis, C., 2000. Multisite ERP implementations. Communications 
[52] of the ACM 43 (4), 42-47.

[53] Menezes, J., Gusmão, C., \& Moura, H. (2019). Risk factors in software development projects: a systematic literature review. Software Quality Journal, 27(3), 11491174.

[54] Nah F.F-H., Lau J.L-S., Kuang J., "Critical factors for successful implementation of enterprise systems", Business Process Management Journal, Catchword, vol. 7, pp. 285-296, 2001.

[55] Neufeld, D. J., Dong, 1., \& Higgins, C. (2007) Charismatic leadership and user acceptance of information technology. European Journal of Information Systems 16(4), 494-510.

[56] Niazi, M., Babar, M. A., \& Verner, J. M. (2010). Software process improvement barriers: A cross-cultural comparison. Information and Software Technology, 52, $1204-1216$

[57] Niazi, M., Mahmood, S., Alshayeb, M., Riaz, M. R., Faisal, K., Cerpa, N., ... \& Richardson, I. (2016). Challenges of project management in global software development: A client-vendor analysis. Information and Software Technology, 80, 1-19.

[58] Nisyak, A. K., Rizkiyah, K., \&Raharjo, T. (2020). Human Related Challenges in Agile Software Development of Government Outsourcing Project. In 2020 7th International Conference on Electrical Engineering, Computer Sciences and Informatics (EECSI) (pp. 222229). IEEE

[59] Pasha, M., Qaiser, G., \& Pasha, U. (2018). A critical analysis of software risk management techniques in large scale systems. IEEE Access, 6, 12412-12424.

[60] Patton, M. Q. (2002). Qualitative research \& evaluation methods (3. ed.). Thousand Oaks, London, U.K.: Sage Publications.

[61] Pickard, A. J. (2013). Research methods in information (2. ed.). London: Facet Publishing.

[62] DOI: https://doi.org/10.29085/9781783300235.

[63] Ragu-Nathan, B., Apigian CH., Ragu-Nathan, T., and TU, Q. (2004) A path analytic study of the effect of top management support for information systems performance. Omega 32(6), 459-471.

[64] Ramasubbu, N. (2013). Governing software process improvementsin globally distributed product development. IEEE Transactions on Software Engineering, 40(3), 235-250.

[65] Runesson, P., Host, M.,: Guidelines for conducting and reporting case study research in software engineering. Empr. Software, Eng. 14, 131-164 (2009).

[66] Rupaliya, J., Trikha, A., \& Kumar, R. (2016). Evaluation of the progress in software development process and the reasons for delayed delivery. Evaluation, 3(11).

[67] Staehr, L. (2010) Understanding the role of managerial agency in achieving business benefits from ERP systems. Information Systems Journal 20(3), 213-238.

[68] Schwandt T.A. (2001). Dictionary of qualitative inquiry. Thousand Oaks, CA: SAGE Publications.

[69] Shao, Z., Feng, Y., and Hu, Q, (2016). Effectiveness of Top Management Support in Enterprise Systems Success: A Contingency Perspective of Fit Between Leadership Style and System Life-Cycle,\| European Journal of
Information Systems, 25(2), 131-153.

[70] Singh, A. S. (2014). Conducting case study research in non-profit organisations. Qualitative Market Research: An International Journal, 17, 77-84.

[71] Smith, J. A. (2004). Reflecting on the development of interpretative phenomenological analysis and its contribution to qualitative research in psychology. Qualitative research in psychology, 1(1), 3954.

[72] Sony, M., \&Naik, S. (2020). Critical factors for the successful implementation of Industry 4.0: a review and future research direction. Production Planning \& Control, 31(10), 799-815.

[73] Swink, M. (2000). Technological innovativeness as a moderator of new product design integration and top management support, J PROD INNOV MANAG 2000, 17, 208-220.

[74] Tobin, G.A., \& Begley, C.M. (2004). Methodological rigour within a qualitative framework. Journal of Advanced Nursing, 48, 388-396.

[75] van Kelle, E., Visser, J., Plaat, A., \& van der Wijst, P. (2015). An empirical study into social success factors for agile software development. In 2015 IEEE/ACM 8th International Workshop on Cooperative and Human Aspects of Software Engineering (pp. 77-80). IEEE.

[76] Wang, S., Wang, H., \& Wang, J. (2019). Exploring the effects of institutional pressures on the implementation of environmental management accounting: Do top management support and perceived benefit work? Business Strategy and the Environment, 28(1), 233-243.

[77] Wagner, R.(2018). How to engage top management in projects and management. International Project Management Association IPMA. Retrieved from https://www.ipma.world/engage-top-managers-projectsproject-management/.

[78] Welshan, G., : Interpretive case study in IS research: nature and method. Euro. J. Inf. Syst. 4,74-81 (1995).

[79] Wiener, M., Cram, A. and Remus, U. (2017). The View From the Top - How Senior Executives Exercise Control Over Information Systems Projects to EnhancePerformance, Proceedings of the 25th European Conference on Information Systems (ECIS), No. July, pp. $1423-1438$

[80] Young, R., \& Jordan, E. (2008). Top management support: Mantra or necessity?

[81] International Journal of Project Management, 26(7), 713725 .

[82] Yunus, Y. M., Aman, A., \&Keliwon, K. B. (2019). The Role of Business Leaders in Information Technology Innovation in the New Era of Disruptive Technology. Asian Journal of Accounting and Governance, 12.

[83] Zwilkael, O. (2008a). Top management involvement in project management; Exclusive supportpractices for different project scenarios, International journal of managing projects in business,2008, 1(3), 387-403.

[84] Zwilkael, O. (2008b), "Top management involvement in project management: A cross country study of the software industry", International journal of managing projects in business, 2008, 1 (4), 498-511. 